\title{
A global wave parameter database for geophysical applications. Part 1: Wave-current-turbulence interaction parameters for the open ocean based on traditional parameterizations
}

\author{
Nicolas Rascle ${ }^{a, b}$, Fabrice Ardhuin ${ }^{a,}{ }^{*}$, Pierre Queffeulou ${ }^{c}$ and Denis Croizé-Fillon ${ }^{c}$ \\ a Centre Militaire d'Océanographie, Service Hydrographique et Océanographique de la Marine, 29609 Brest, \\ France \\ ${ }^{b}$ Laboratoire de Physique des Océans, Université de Bretagne Occidentale, 29000 Brest, France \\ c Laboratoire d'Océanographie Spatiale, Ifremer, 29280 Plouzané, France \\ *: Corresponding author : Fabrice Ardhuin, email address : ardhuin@shom.fr
}

\begin{abstract}
:
Ocean surface mixing and drift are influenced by the mixed layer depth, buoyancy fluxes and currents below the mixed layer. Drift and mixing are also functions of the surface Stokes drift $U_{\text {ss }}$, volume Stokes transport $T_{\mathrm{S}}$, a wave breaking height scale $H_{\mathrm{swg}}$, and the flux of energy from waves to ocean turbulence $\Phi_{\mathrm{oc}}$. Here we describe a global database of these parameters, estimated from a wellvalidated numerical wave model, that uses traditional forms of the wave generation and dissipation parameterizations, and covers the years 2003-2007. Compared to previous studies, the present work has the advantage of being consistent with the known physical processes that regulate the wave field and the air-sea fluxes, and also consistent with a very large number of in situ and satellite observations of wave parameters. Consequently, some of our estimates differ significantly from previous estimates. In particular, we find that the mean global integral of $\Phi_{\mathrm{oc}}$ is $68 \mathrm{TW}$, and the yearly mean value of $T_{\mathrm{S}}$ is typically $10-30 \%$ of the Ekman transport, except in well-defined regions where it can reach $60 \%$. We also have refined our previous estimates of $U_{s s}$ by using a better treatment of the high frequency part of the wave spectrum. In the open ocean, $U_{s s} \simeq 0.013 U_{10}$, where $U_{10}$ is the wind speed at $10 \mathrm{~m}$ height.
\end{abstract}

Keywords: Surface gravity waves; Air-sea fluxes; Surface drift; Ocean mixing

\section{Introduction}

Waves constitute the essential gearbox between the atmosphere and ocean, allowing large fluxes of energy, momentum, and gases across the air-sea interface. The wave properties are well known to experts, at least qualitatively (e.g. 
Donelan, 1998), but are often ignored by others. For example, the magnitude of the fluxes of energy from the atmosphere to the wave field are poorly known. In a review of the global ocean energy budget, Wunsch and Ferrari (2003) give a value of $20 \mathrm{TW}$ for the global average of the wind to wave energy flux. As will be shown here this is probably underestimated by a factor 3. Given the recent interest in storm-induced mixing (Quéré et al., 2007; Sriver and Huber, 2007), a serious estimation of the wave-related components and fluxes in the Earth system is needed.

The ocean surface layer is influenced by different characteristics of the waves. These waves cover a vast range of scales, from individual waves over $20 \mathrm{~m}$ high and wavelengths over $300 \mathrm{~m}$, to short capillary-gravity waves of a few centimeters in height and wavelength. Such a complex multi-scale forcing may be characterized using a few key parameters. These include the surface Stokes drift $U_{\mathrm{ss}}$, and a scale $H_{b}$ for the height of large breaking waves which likely controls the sub-surface level of turbulence together with the rate of waves energy dissipation per unit surface $\Phi_{\text {oc }}$. A few estimates of these parameters have been published, usually based on indirect measurements with a limited set of observations (e.g. Stacev and Pond, 1997). Assumptions are thus often called upon without a clear understanding of their consequences. In particular, the wave age that characterizes the development of the sea state, is of critical importance for a precise estimation of the Stokes drift and the breaking wave height. In spite of this, the wave field if often assumed to be a fully developed wind sea (e.g. McWilliams and Restrepo, 1999), although this may well be the least likely type of sea state. Indeed, in several years of data Pierson and Moskowitz (1964) could only find about 20 instances of fully developed seas (Alves et al., 2003).

In the absence of any other information, the ocean circulation modeler is left to extrapolate these values in uncharted waters, with likely large errors. An interesting parallel is provided by the problem of the estimation of the wind stress over the ocean, a parameter measured much more frequently than surface drift or near-surface turbulence. Drennan et al. (2005) clearly showed that empirical relations derived for deep water conditions were unable to reproduce the Ris $\varnothing$ Air-Sea Exchange (RASEX) shallow water wind stresses, because these simple analytical expressions do not include mechanical constraints on the wind stress, i.e. energy and momentum must be passed to the ocean through the waves in a way consistent with their known physical properties. A numerical wave model, even if based on an imperfect knowledge of the detailed physical processes, will capture at least some of these constraints. A model may thus provide the best estimate of the wave spectrum and the energy fluxes in and out of the wave field, in a way consistent with wave observations.

A preliminary estimation of then atmosphere-wave-ocean fluxes, including $\Phi_{\mathrm{oc}}$, and of the Stokes volume transport $T_{S}$, was performed by Janssen et al. (2004). 
However, values were only given for the month of January 2003. Further, that model only resolved explicitly waves of periods larger than 2.5 s, i.e. waves longer than $10 \mathrm{~m}$. As a result, no wind sea can be modelled for winds with a $10 \mathrm{~m}$ velocity $U_{10}$ under $5 \mathrm{~m} \mathrm{~s}^{-1}$. Following recent improvements in numerical wave models at the global scale (e.g. Janssen, 2007), we extend that study and provide a general global and regional-scale database of waverelated parameters.

In section 2 , we review the parameters needed to represent the wave-induced mixing and surface drift. The numerical wave model and its validation in terms of commonly observed quantities such as the significant wave height $H_{s}$, mean period $T_{m 02}$ are described in section 3 , with a brief discussion of unresolved problems and sources of errors. In section 4 we then discuss in turn each of these parameters and provide a fresh estimation of their magnitude and variability. We insist that all wave-related parameters are highly variable in time and space due to the intermittent nature of the wave field. In this context, averages may not be meaningful, even in terms of order of magnitude. We thus warmly encourage the reader to access our database at ftp://ftp.ifremer.fr/ifremer/cersat/products/gridded/wavewatch3/, instead of stopping at the crude relationships, reviewed here, that relate these parameters to the wind speed. A short guide to the database is given in Appendix A. Better still, running a wave model is simple enough and should be done when investigating the ocean circulation at regional scales. The necessary input files and model setup are also provided in the database with the end results over a few regions. We then present, in section 5, some illustration of the usage of this data for the modelling of the ocean mixed layer and finish with perspectives on the improvements and evolutions of the database.

\section{Which parameters for wave-induced mixing ?}

The classical view on the ocean surface layer is a transposition of the atmospheric boundary layer over land, which is well described by Monin-Obukhov theory, as verified in the Kansas experiments (Businger et al., 1971). Turbulent kinetic energy (TKE) is produced by velocity shears and unstable stratification, and may be destroyed by stable stratification and viscous dissipation. In stably stratified cases, this leads to a description of the mixed layer depth through a competition between the shear production by the mean current and the buoyancy damping, leading to definitions of Richardson numbers based on their ratio.

A significant difference in the ocean surface layer is that the surface is neither rigid nor flat due to the presence of waves. Since the early 1990's many field experiments have demonstrated that waves profoundly modify the ocean surface layer (e.g. Agrawal et al., 1992), with no counterpart in the atmospheric 
boundary layer. Although the momentum flux profiles generally agree with the land data in the mean (Fairall et al., 2003), deviations are also evident at low and high wind, showing a clear departure from Monin-Obukhov theory (Jim Edson, personal communication, 2007), due to a variety of wave-related processes.

Firstly the surface generation of TKE associated with wave breaking dominates by far the near-surface TKE production by the current shear (e.g. Terrav et al., 1996). This strongly modifies the classical competition between shear production and buoyancy damping. For instance Noh (1996) showed that this surface flux of turbulence is a necessary ingredient to obtain a thermocline in the presence of both wind and stabilizing buoyancy flux. This explains why the diurnal ocean surface layer exhibits a thermocline, while the nocturnal atmospheric boundary layer, its atmospheric counterpart, does not.

Secondly, most of the momentum flux $\tau_{a}$ from the atmosphere to the ocean transits through the wave field, with an input given by the form drag (or wave-supported stress) $\tau_{w}$ and an output to the current field in the form of wave breaking $\tau_{\text {oc }}$. Only a small fraction of $\tau_{a}$, except at very low winds, goes directly from the atmosphere to the ocean via the mean viscous stress at the surface (Dobson, 1971; Snvder et al., 1981; Donelan, 1998). However, most of the momentum flux is rapidly passed to the currents as waves break.

Technically, the wind stress applied to the ocean for computing the mean current should be reduced to $\tau_{\mathrm{oc}}$, to account for the fraction radiated away by the wave field, but this is typically less than $3 \%$ of $\tau_{a}$ (Donelan, 1998; Janssen et al., 2004). Nevertheless, even if most of the momentum and energy gained by the waves is quickly released to the ocean (Donelan, 1998), the small fraction radiated in the wave field is important. First of all, it is the energy that is eventually dissipated in the surf, and available for potential conversion to electric power. Further, from an ocean circulation point of view, the associated wave momentum ${ }^{1}$ radiated with the wave field further interacts with the mean flow.

\subsection{Wave-induced mixing in the near-surface zone}

Whitecaps at the ocean surface provide an intense source of TKE compared to the shear of the mean current (Terrav et al., 1996). This process has been

1 The phrase wave momentum is used here instead of the correct wave pseudomomentum, the reader is referred to McIntvre (1981) for a detailed discussion of these concepts. 
successfully modelled with simple two-equation models for the turbulence closure(e.g. Mellor and Yamada, 1982), by adding a TKE surface flux $\left(\Phi_{\text {oc }}\right)$ coming from the dissipation of surface waves and by setting the near-surface mixing length at the surface $\left(z_{0 w}\right)$ to a relatively large value, of the order of the significant wave height $H_{s}$ (Craig and Banner, 1994; Terrav et al., 1996; Burchard, 2001; Acreman and Jeffery, 2007). This wave height should be further restricted to the wind sea only since swells do not break in deep water, and may also be a function of the wave age. Given the ongoing debate on the scaling of $z_{0 w}$ we did not go further the straightforward estimation of the of a wave height scale $H_{\text {swg }}$, defined below, leaving to ocean modelers the choice of the exact parameterization.

In summary the modelling of ocean near-surface mixing requires the flux of TKE to the oceanic turbulence $\Phi_{\text {oc }}$, and the sub-surface roughness $z_{0 w}$, with a proxy given by $H_{\mathrm{swg}}$.

\subsection{Wave-induced mixing through the whole mixed layer}

Finally, the wave momentum and its interactions with the current are known to be at the origin of Langmuir circulation (Langmuir, 1938; Craik and Leibovich, 1977; Garrett, 1976), which are believed to be the dominant vertical mixing mechanism for momentum and tracers, through the whole mixed layer (Smith, 2001; Noh et al., 2004), except probably in the near-surface zone, and an important process for deepening the mixed layer (Li et al., 1995).

Langmuir turbulence is reported to occur for small values of the Langmuir parameter $L a=\sqrt{u_{\star} / U_{\mathrm{ss}}}$, where $u_{\star}$ is the air-side friction velocity, and observations suggest that the turbulent velocity $w_{\text {rms }}$ scales with the surface Stokes drift (Smith, 1998). We note that the vertical shear of the Stokes drift is absent from these dimensional analysis, whereas the tilting of the vorticity of the current by the Stokes drift shear is a key ingredient in recipes for Langmuir circulation. Recently, Harcourt and D'Asaro (2006) proposed a revised Langmuir parameter $L a_{\mathrm{St}}$, in which the mean Stokes drift between the surface and one fifth of the mixed layer depth is used instead of its surface value. That number was chosen to include in the dimensional analysis the ratio of the mixed layer depth to the Stokes depth, which characterizes the vertical shear of the Stokes drift through the mixed layer. Based on LES simulations, the turbulent velocity of the Langmuir cells was found to depend on that modified Langmuir number by the formula $w_{r m s} \propto u_{\star} L a_{\mathrm{St}}^{-2 / 3}$. These authors further argued that the observations hardly exhibit such a trend because of inverse correlations between winds speeds and wave ages in the field measurements. 
Thus a proper parameterization of the sub-surface mixing requires estimations of the vertical profile of the Stokes drift vector. At the very least, this may be reduced to its surface value $U_{\mathrm{ss}}$, with a measure of the shear given by the combination of $U_{\text {ss }}$ and the wave-induced volume transport $T_{S}$. Besides, the TKE produced by the straining of turbulence due to the wave field, of the order of $\tau_{a} U_{\mathrm{ss}}$ (Ardhuin and Jenkins, 2006) gives an upper bound on the flux of energy from the waves to the Langmuir Circulations (LC), an amount of energy partly available for the erosion of the thermocline. The fraction of that energy flux actually used to increase the mixed layer depth may be better defined by analyzing the contribution of the difference scales of LC rolls to the vertical flux of momentum. One would expect that, with a fraction $p$ of momentum flux carried by the biggest rolls, the TKE flux penetrating to the base of the mixed layer is of the order of $p \tau_{a} U_{\mathrm{ss}}$.

\subsection{Wave-induced drift and transport}

Although the time-average transport due to waves is cancelled by the StokesCoriolis force (Hasselmann, 1970; Xu and Bowen, 1994; Ardhuin et al., 2004; Rascle et al., 2006), a proper modelling of surface drift does require an estimate of the surface Stokes drift $U_{\mathrm{ss}}$. The Stokes volume transport $T_{S}$ may be used to diagnose an upper bound on the possible non-stationary waveinduced transport. The wave-induced mass transport $M^{w}=\rho_{w} T_{S}$, where $\rho_{w}$ is the water density, also comes into the general wave-current interaction equations, whether formulated in terms of the total momentum (Phillips, 1977)

or in terms of the mean flow momentum only (Garrett, 1976; Smith, 2006; Ardhuin et al., 2008).

\section{Wave model and validation of standard parameters}

\subsection{Model description}

All these parameters, $\Phi_{\mathrm{oc}}, H_{\mathrm{swg}}, U_{\mathrm{ss}}$, and $T_{S}$ may be obtained from numerical wave models. One should be careful that such models are mostly verified in terms of significant wave height $H_{s}$ and peak or mean period only $\left(T_{p}\right.$ or $\left.T_{\mathrm{m} 02}\right)$, so that other parameters, in particular those related to the high-frequency end of the spectrum may not be well estimated and noisy. The results shown here are obtained with the WAVEWATCH III (WWATCH) code in its version 3.13 (Tolman, 2007), using the parameterization of Bidlot et al. (2005). In practice, this is activated with the ST3 switch, and we further set the wind-wave growth parameter $\beta_{\max }$ to 1.25 via the SIN3 namelist. All other model parameters are 
default values. The code was further modified to allow the calculation and output of $\Phi_{\mathrm{oc}}, H_{\mathrm{swg}}, U_{\mathrm{ss}}$, and $T_{S}$. This modification will likely be included in a later version 4.xx of WWATCH, and is otherwise available from the authors.

Our model configuration is global $\left(80^{\circ} \mathrm{S}\right.$ to $\left.80^{\circ} \mathrm{N}\right)$ with $1^{\circ}$ resolution, using a combination of ETOPO5 data for the bathymetry (Sloss, 1993), and the GSHHS coastline database (Wessel and Smith, 1996) for producing the blocking mask which is used to represent subgrid islands (Tolman, 2003). The modelled spectra are discretized with 32 frequency exponentially spaced between $0.0373 \mathrm{~Hz}$ and $f_{\max }=0.716 \mathrm{~Hz}$, and 24 directions. This model is forced with $10-\mathrm{m}$ winds 6-hourly analysis and daily sea ice concentrations from the European Center for Medium-Range Weather Forecasting (ECMWF). This particular model and configuration have been extensively validated against all in situ sensors reporting to the World Meteorological Organization (WMO) Global Transmission System, and all satellite altimeters (see Appendix B for methods) over the period January 2004 to October 2007, which is covered by the database. Further validation with SAR wave mode (Kerbaol et al., 1998) and image mode data (Collard et al., 2005) will be presented elsewhere. This model configuration (code, bathymetry and forcing) was chosen because, without using wave data assimilation, it gives the lowest root mean square errors (RMSE) on significant wave heights at buoys (close to results obtained with version 2.22 of WWATCH, which are reported in Bidlot et al., 2007b), and illustrated in figure 1, and the smallest random errors against altimeter measurements (figure 2).

In situ and altimeter data provide two very complementary view of the quality of the wave field. Buoys have a very good time resolution and provide information on both the energy content of the wave field, represented by $H_{s}$, and the wave scales represented by the mean or peak period, or the full frequency spectrum. Many buoys also measure wave directional properties. Unfortunately, buoys are generally deployed close to continents and, in many cases, in coastal waters poorly resolved in a global model. Although the sea state in coastal areas is largely dominated by global scale wave fields, a proper validation would require an additional postprocessing of the global model presented here, using nested coastal models, for example based on ray-tracing, and potentially including specific coastal processes (e.g. Ardhuin et al., 2003; Magne et al., 2007). Further, many regions of the world are poorly instrumented, and, when they are, the data is often not reported to the World Meteorological Organization (WMO). We have thus chosen to use the Joint Commission on Oceanography and Marine Meteorology (JCOMM) intercomparison data for the year 2006 (Bidlot et al., 2002, 2007b) which includes 214 buoys, with data for $H_{s}$ and $T_{p}$ or $T_{\mathrm{m} 02}$ (depending on instrumentation packages), averaged over a 5 hour window every 6 hours (J.-R. and Holt, 2006).

The $1^{\circ}$ model configuration used here gives a generally negative bias of the or- 

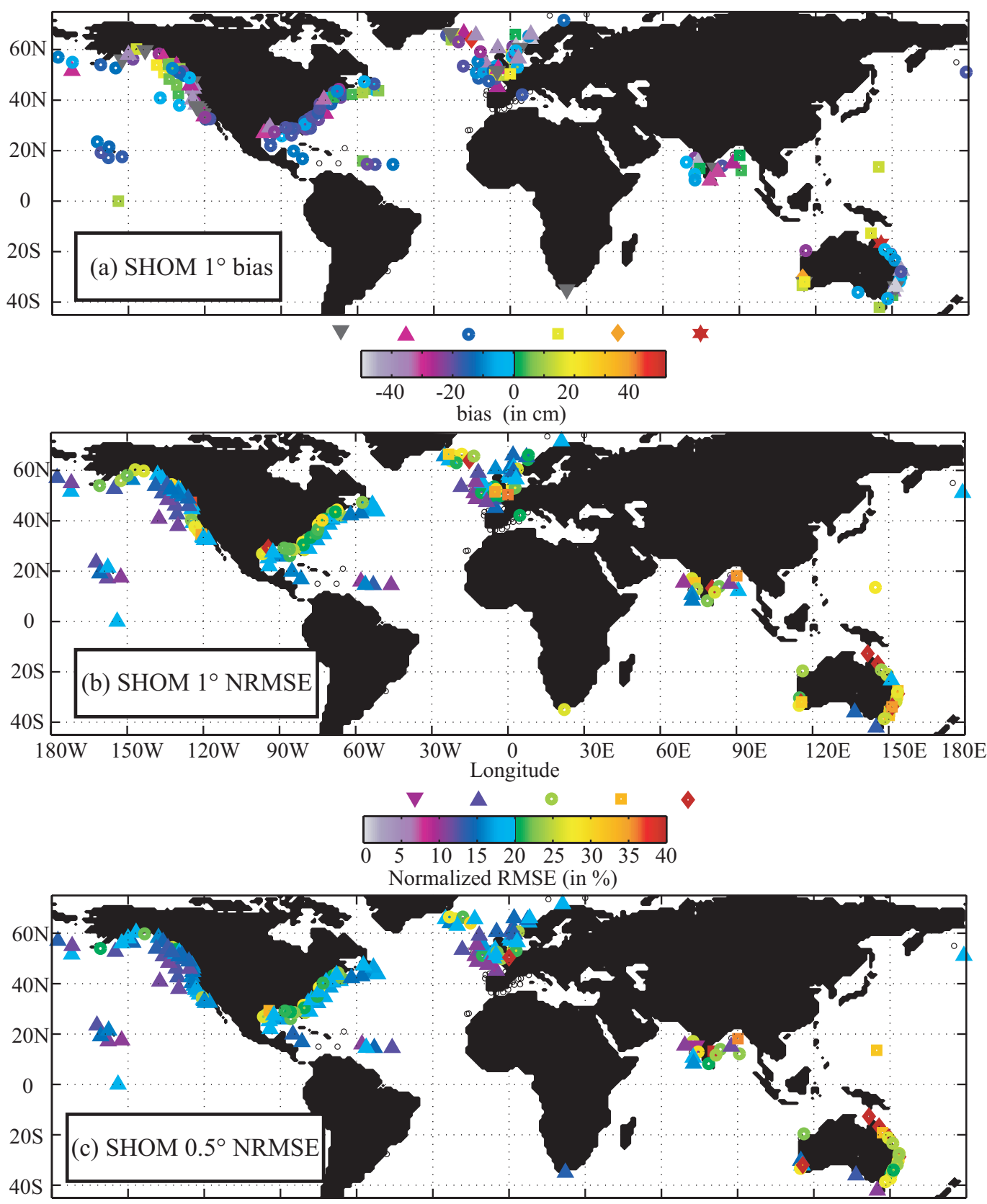

Fig. 1. Statistics for the year 2006. (a) bias for $H_{s}$ at in situ locations. Symbols $\nabla$, $\triangle, \circ, \square, \diamond$ and $\star$ correspond to values in the ranges $x<-50,-50 \leq x<-25$, $-25 \leq x<0,0 \leq x<25,25 \leq x<50,50 \leq x$, respectively. (b) Normalized RMSE for $H_{s}$ at in situ locations. Symbols $\nabla, \triangle, \circ, \square$, and $\diamond$ correspond to values in the ranges $0 \leq x<10,10 \leq x<20,20 \leq x<30,30 \leq x<40,40 \leq x$. (c) Same as (b) but for a higher resolution model.

der of $10 \mathrm{~cm}$ (figure 1.a), and a normalized root mean square errors (NRMSE ${ }^{2}$ ) between 10 to $25 \%$ at most locations (figure 1.ab, table 1 ).

$\overline{2}$ This is the RMS difference divided by the RMS observation of a given location 


\begin{tabular}{ccccccc}
\hline Model & Parameter & $x<10$ & $\leq x<20$ & $\leq x<30$ & $\leq x<40$ & $\leq x$ \\
\hline SHOM $^{\circ}$ & NRMSE for $H_{s}$ & 0 & 51 & 36 & 8 & 5 \\
${\text { SHOM } 1^{\circ}}$ & NRMSE for $T$ & 9 & 41 & 34 & 11 & 4 \\
\hline${\text { SHOM } 0.5^{\circ}}$ & NRMSE for $\mathrm{H}_{s}$ & 1 & 63 & 29 & 3 & 3 \\
SHOM 0.5 & NRMSE for $T$ & 9 & 39 & 36 & 13 & 4 \\
\hline ECMWF & NRMSE for $\mathrm{H}_{s}$ & 12 & 62 & 17 & 3 & 6 \\
ECMWF & NRMSE for $T$ & 11 & 60 & 10 & 4 & 6 \\
\hline
\end{tabular}

Table 1

Percentage of buoys with a given statistical parameter $x$ in a given range of values. Fore reference results from the operational ECMWF analysis are also given.

Errors are largest at coastal buoys, mostly due to the coarse discretization of the coastline in the model. Tests with a $0.5^{\circ}$ model show a general reduction of the errors (figure 1.c), with a NRMSE that is, on average, 2.6 percentage point above the ECMWF operational analysis (in which altimeter data is assimilated). Our use of a coastline to define subgrid islands, instead of a bathymetry data, is the likely reason for a better performance of the present model at several Australian buoys and the island of Guam, compared to ECMWF operational analysis.

However, for our present purpose, a global-scale climatology of wave-related parameters, it is most important to verify the quality of the model in the open ocean. Using data from three altimeter missions over the period 2004 to 2006 provides a large validation data base with enough data in $1^{\circ}$ by $1^{\circ}$ squares (the model resolution) to allow the estimation of reliable statistics (fig. 2, see appendix B).

The altimeter reveals particularly well a large bias in wave heights in the Eastern Pacific. This bias is clearly associated with the WAM-type dissipation and input parameterizations (Komen et al., 1984), since it was already present in WAM Cycle 3 (Tolman, 2002, figure 5), and was only slightly reduced with the latest ECWAM parameterization (Bidlot et al., 2005, figure 8).

For reference the operational wave model used at the U.S. National Ocean and Atmosphere Administration (NOAA) National Center for Environmental Prediction (NCEP) does not have this East Pacific bias, thanks to the parameterization of swell attenuation. However, NCEP's model produces significantly larger random errors outside of the tropical ocean, at least for the their year 2000 compared to our year 2004 (see figure 4 in Tolman 2003, and compare to our figure 2). This better quality of the model, compared to NCEP's, in terms of random errors is consistent with the wave height and period statistics at the buoys (Bidlot et al., 2007a). Although the driving wind fields are different, it is likely that the better agreement is partly due to a better es- 

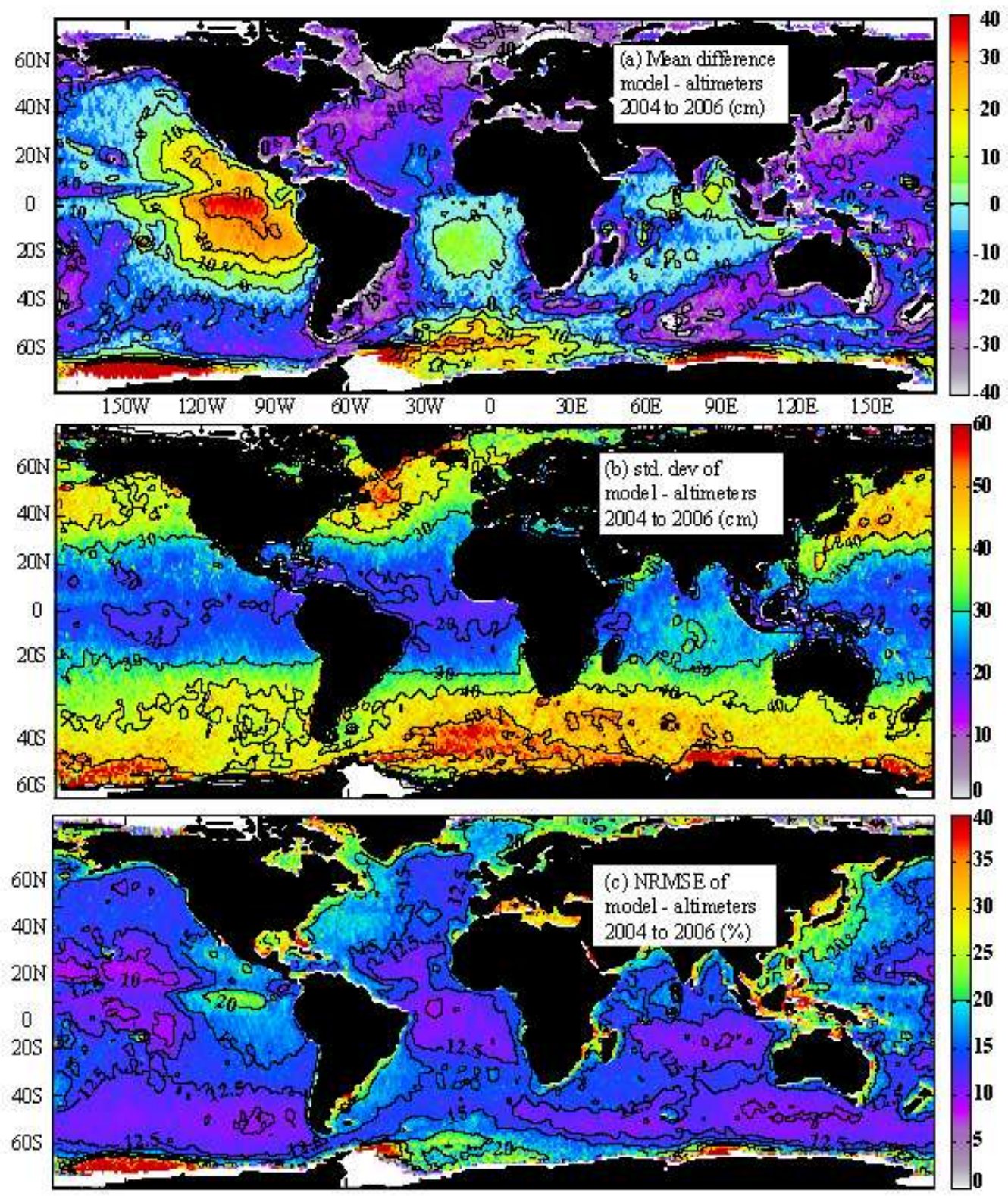

Fig. 2. Statistics for 2004 to 2006, combining data from JASON, ENVISAT and GEOSAT-Follow On (GFO). See Appendix B for satellite data analysis methods.

timation of the magnitude of the wind input and dissipation source terms. Ardhuin et al. (2007) showed that Tolman and Chalikov (1996)'s wind input and dissipation parameterizations (used at NCEP) yield large biases in mean direction at the frequency peak in slanting fetch conditions, which was interpreted as evidence for too weak a forcing in young wave conditions. In this respect, the parameterizations of Bidlot et al. (2005) provide a better fit to short fetch wave directions. It is thus likely that the global scale random errors are smaller with that latter parameterization because it produces a more 
realistic timescale for the wave field evolution.

However, the present model gives some important errors on the wave periods, in particular a large persistent positive bias in the North-East Pacific (fig. 3).
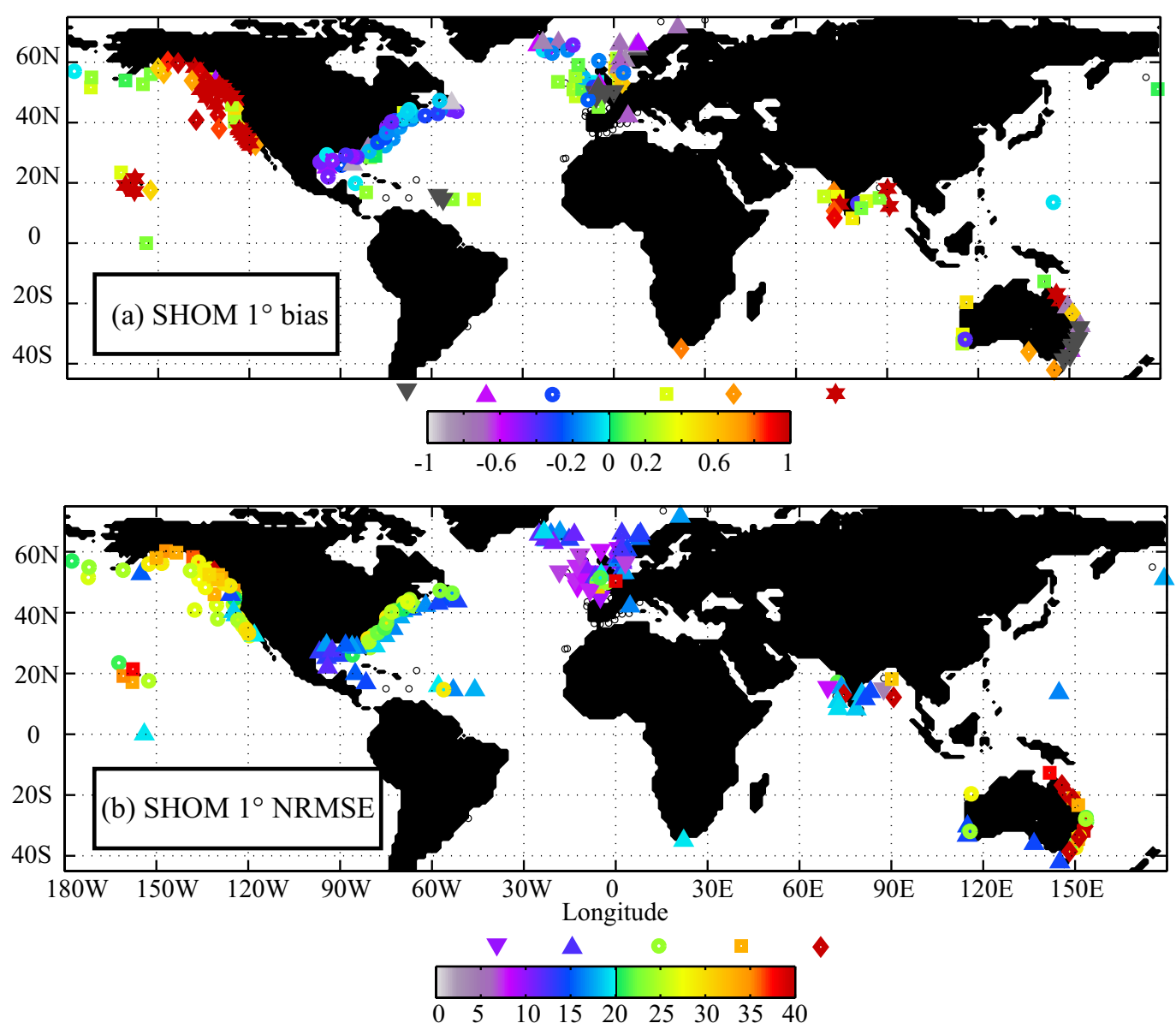

Fig. 3. Statistics for the year 2006. (a) bias for $T_{\mathrm{m} 02}$ (most European buoys) or $T_{p}$ (all other buoys) at in situ locations. Symbols $\nabla, \triangle, \circ, \square, \diamond$ and $\star$ correspond to values in the ranges $x<-1 .,-1 \leq x<-0.5,-0.5 \leq x<0,0 \leq x<0.5$, $0.5 \leq x<1,1 \leq x$, respectively. (b) Normalized RMSE for $T_{\mathrm{m} 02}$ (most European buoys) or $T_{p}$ (all other buoys). Symbols $\nabla, \triangle, \circ, \square$, and $\diamond$ correspond to values in the ranges $0 \leq x<10,10 \leq x<20,20 \leq x<30,30 \leq x<40,40 \leq x$.

Clearly the model is not perfect and some further tuning of parameters such as the wind-wave coupling coefficient $\beta_{\max }$ could be done. Increasing only $\beta_{\max }$ would generally reduce the negative bias for $H_{s}$ but also reduce the correlation coefficients for $H_{s}$, and increase the bias on the periods. The parameter settings chosen here are thus a compromise (with a relatively good performance on the U.S. West coast), before a completely new set of parameterizations is adjusted. 


\subsection{Known model deficiencies}

The model errors can be traced to three important deficiencies in the parameterization by Bidlot et al. (2005). First and foremost, the parameterization lacks a swell attenuation mechanism (Tolman, 2002). Clear evidence for this are the large biases on $H_{s}$ and $T_{p}$ in the Eastern Pacific (fig. 2). Although this could be attributed to errors in local windsea generation, the fact that this bias is due to swell is confirmed by the analysis of swell fields over large distances using the ERS and ENVISAT wave mode databases (Fabrice Collard, personnal communication 2007). This effect is also noticeable at mid latitudes, with an overestimation of low wave heights $\left(H_{s}<1 \mathrm{~m}\right)$ in in the North East Atlantic (fig. 4).

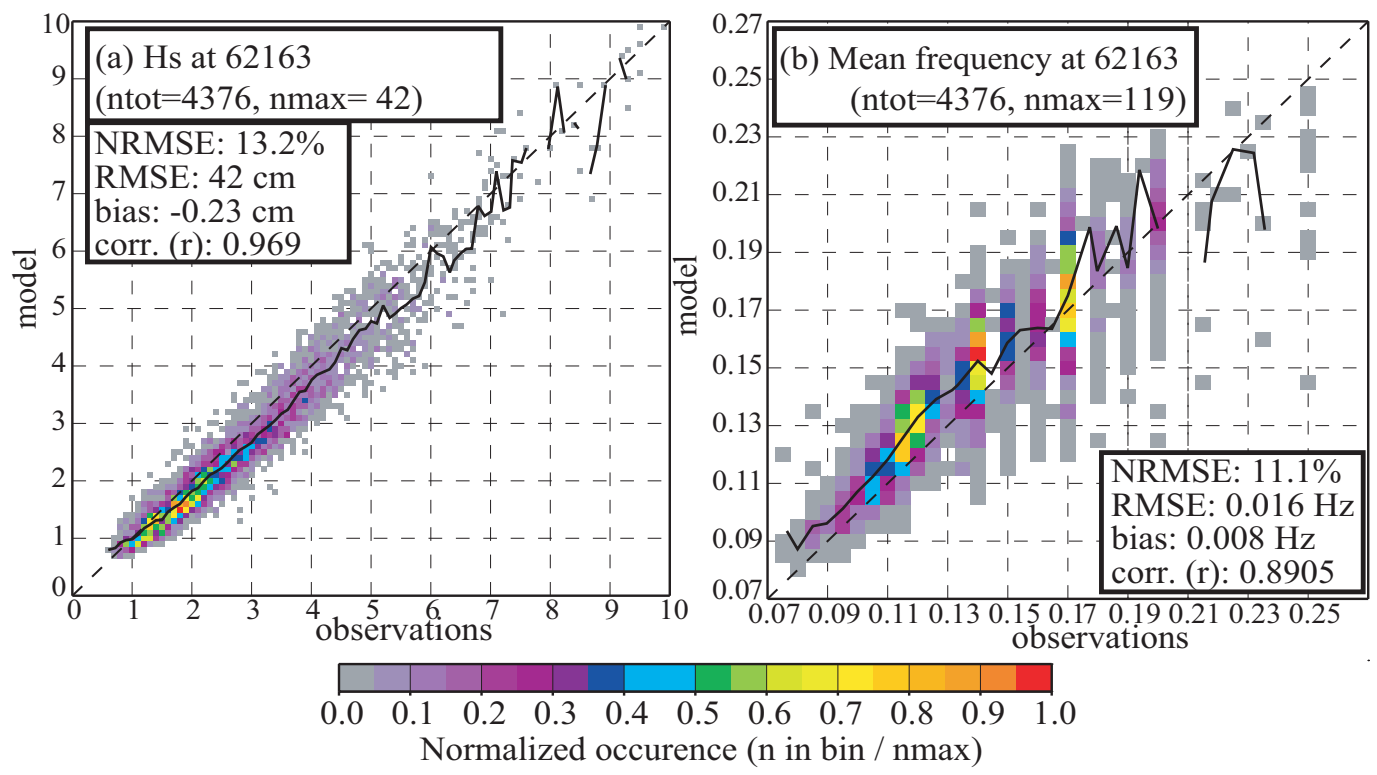

Fig. 4. Statistics for the years 2004 and 2005 at buoy $62163\left(47^{\circ} 30^{\prime} \mathrm{N}, 8^{\circ} 24^{\prime} \mathrm{W}, 200\right.$ $\mathrm{km}$ off the west coast of France). (a) Wave heights, and (b) mean periods. The solid lines shows the mean observed and modelled value in each observation bin.

This is the topic of ongoing work, and this issue should be resolved in the coming year. The processes that cause the swell attenuation are not fully elucidated (Ardhuin and Jenkins, 2006; WISE Group, 2007), but they are likely dominated by the damping of waves due to the strong shears at the air-sea interface (Weber and Førland, 1990; Kudrvavtsev and Makin, 2004), resulting in a wave-driven wind (Grachev et al., 2003). If this is the case, the associated flux of energy is from the wave field back to the atmosphere, and thus irrelevant to the problem of ocean mixing, except for indirect effects through enhanced wind sea generation by the wave-driven wind.

Second, the parameterization leads to an overestimation of the wind stress at 
high winds. For $U_{10}>30 \mathrm{~m} \mathrm{~s}^{-1}$, the drag coefficient $C_{d}$ may exceed 0.04 , about a factor 2 larger that the largest estimates of $C_{d}$ based on in situ observations (Powell et al., 2003). Although this may lead to local biases in the estimation of atmosphere-wave-ocean energy fluxes, the globally average effect is likely to be small, because these high winds are rare. This will be estimated below by using a correction for the overestimation of $C_{d}$.

Third, the parameterization of the windsea evolution is unrealistically sensitive to swell, leading to an overestimation of wind sea growth in the presence of swell (Ardhuin et al., 2007). In the present model, this effect should be strongest when the wind sea and swell frequencies are relatively close.

Finally, the forcing of the model is not perfect either, in particular the ocean currents were neglected here. This is most important where the currents $\mathbf{U}$ are fast relative to either the phase speed $C$ of the waves (in which case refraction and shoaling can be important) or the wind speed $\mathbf{U}_{10}$ (in which case the waves should be generated by the relative wind $\left.\mathbf{U}_{10}-\mathbf{U}\right)$. A preliminary analysis using $0.5^{\circ}$ surface current fields from Mercator's PSY3V1 model (Barnier et al., 2006) shows that in the equatorial region, where the average current can exceed $7 \%$ of the average wind velocity, currents have a significant impact on $H_{s}$ (fig. 5), as already expected by Janssen et al. (2005). Including currents removes most of the small scale structure in the wave height bias over the equatorial current and the north equatorial counter current. In other regions there is an increase of the negative biases, due to the fact that swells are often generated over currents that flow in the wind direction, in particular around the southern Ocean. Taking into account the current thus reduces the relative wind and the wind-wave growth.

In order to remove these errors, a new version of the model is being developed and the wave parameter climatology will be updated when this is done. At present, the new versions that have been tested still give wave height errors slightly larger than the present version and are thus believed to be less realistic also for the other parameters discussed here.

\section{Wave-related parameters}

\subsection{The Surface Stokes drift $U_{\mathrm{ss}}$}

\subsubsection{Stokes drift of non-linear waves}

When considering random waves, the Stokes drift is usually estimated from the wave spectrum assuming that the phases of the wave components are not 


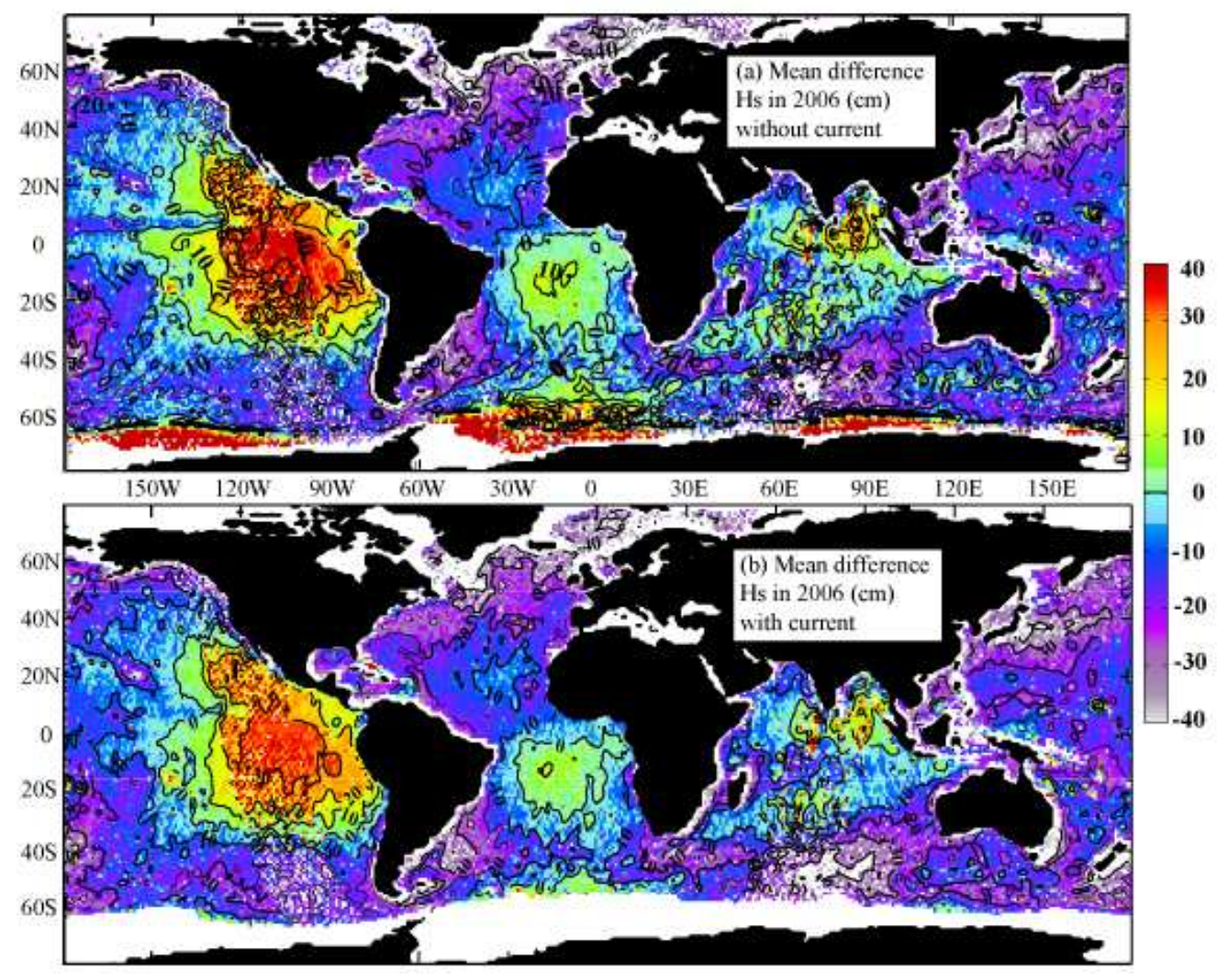

Fig. 5. Bias on $H_{s}$ for 2006, combining data from JASON, ENVISAT and GEOSAT-Follow On (GFO), (a) with the model used here, (b) with the model including forcing by surface currents. See Appendix B for satellite data analysis methods.

correlated (Kenvon, 1969). Here we estimate the error due to that assumption using a streamfunction theory (Dean, 1965; Dalrvmple, 1974) to order 80 and above, with an explicit calculation of drift velocities along streamlines. We consider the case of deep water waves by choosing $k D=4.5$ where $k$ is the wavenumber and $D$ is the water depth. In this case, and when the orbital velocity at the crest $U_{c}$ exceeds $99 \%$ of the phase speed $C$, the surface drift may be $q=1.8$ times the value given by linear theory for the same elevation variance. Such waves are very nearly breaking. In the same case, $U_{s}$ exceeds the linear value at the surface over a depth of about $5 \%$ times the wave height. However, this speed-up factor $q$ due to the wave nonlinearity drops to 1.06 for $U_{c} / C=0.5$, which still corresponds to a very large wave steepness $k H / 2=0.36$, where $H$ is the wave height. Clearly, very few waves in a random sea state are so steep, and we may expect linear wave theory to provide a reliable estimate of the surface drift, with the exception of the effect of breaking waves. 


\subsubsection{Previous estimations of $U_{\mathrm{ss}}$}

We thus use a superposition of linear wave theory results (e.g. Lamb, 1932). In deep water, the surface Stokes drift is

$$
\mathbf{U}_{\mathrm{ss}}=\frac{2}{g} \iint \sigma^{3} E(f, \theta) \mathbf{u}_{\theta} \mathrm{dfd} \theta,
$$

where $\mathbf{u}_{\theta}=(\cos \theta, \sin \theta)$ is the unit vector in the direction of propagation, and $\sigma=2 \pi f$. This expression has been often used improperly. For example, Kenvon (1969) estimated that the surface drift of fully-developed waves could reach $3 \%$ of $U_{10}$, but he defined the wave spectrum for that calculation by a non-classical form of the Pierson and Moskowitz (1964) spectrum.

Further, the surface Stokes drift strongly depends on the shape of the high frequency part (the 'tail') of the spectrum. Therefore these results were reevaluated by Rascle et al. (2006) using the spectrum of Kudrvavtsev et al. (1999), which was designed for remote sensing applications and is therefore expected to be realistic in the high frequency part than the spectrum of Pierson and Moskowitz (1964). It was obtained that the Stokes drift can reach a maximum value of $1.2 \%$ of the wind speed. This ratio was found to be maximum for high wind speeds (Rascle et al., 2006, fig. 2b). However, that spectrum lacks the overshoot of the spectral peak and appears less realistic for the long waves.

\subsubsection{Estimation of $U_{\mathrm{ss}}$ with a wave model}

Because the wave field is almost never fully developed, and because swells should also contribute to the drift, it is interesting to estimate the Stokes drift for real sea states. The waves are only resolved by the model over the frequency range of the most energetic waves, with a maximum frequency of $f_{\max }=0.72 \mathrm{~Hz}$. Since smaller waves can have a non-negligible contribution on the surface Stokes drift, we will extend analytically the spectrum to higher frequencies.

Following Phillips (1958), we define the non-dimensional Phillips parameter at $f_{\max }$ as

$$
\alpha_{\mathrm{Ph}}\left(f_{\max }, \theta\right)=\frac{E\left(f_{\max }, \theta\right) \sigma^{5}}{2 \pi g^{2}} .
$$

We then extend the spectrum $E(f, \theta)$ beyond $f_{\max }$ by assuming that $\alpha_{P h}(f, \theta)=$ $\alpha_{P h}\left(f_{\max }, \theta\right)$ for $f \geq f_{\max }$, which corresponds to a $f^{-5}$ decrease of $E(f, \theta)$ (see Long and Resio, 2007, for an up to date discussion of the spectral shape.). The high frequency contribution to the surface Stokes drift $U_{\text {ss }}$ writes 


$$
\mathbf{U}_{\mathrm{ss}}^{+}=\frac{g}{\pi} \frac{1}{f_{\max }}\left[\int_{0}^{2 \pi} \alpha_{\mathrm{Ph}}\left(f_{\max }, \theta\right) \mathbf{u}_{\theta} \mathrm{d} \theta\right]
$$

which is typically of the order of $0.004 U_{10}$ for $f_{\max }=0.4 \mathrm{~Hz}$ and $0.0025 U_{10}$ for $f_{\max }=0.7 \mathrm{~Hz}$ (fig. 7).

As a consistency check of this $f^{-5}$ extension, we followed the method employed by Elfouhailv et al. (1997) who connected the low-frequency spectrum of Donelan and Pierson (1987) to a high frequency spectrum constrained by a variety of observations. This method was shown to give good results in terms of mean square slope (mss) which is the fourth moment of the frequency spectrum and depends both on the low and on the high frequency parts of the spectrum. Because $U_{\mathrm{ss}}$ is close to the third moment of the frequency spectrum, it is expected to behave similarly to the mss, and we applied the method of Elfouhaily et al. (1997) to extend the WWATCH spectrum. The resulting composite spectrum ('WW3ECKV') is obtained by connecting the $E(f)$ from WWATCH, for $f<f_{\max }$, to the high frequency part spectrum of Elfouhaily et al. (1997) (their eq. 30 and 40). A cut-off at $10 k_{p}$, where $k_{p}$ is the peak wavenumber, is used by Elfouhaily et al. (1997) to limit the energy containing part of the spectrum. It writes (their eq. 32)

$$
\exp \left\{-\frac{\Omega}{\sqrt{10}}\left[\sqrt{\frac{k}{k_{p}}}-1\right]\right\} .
$$

We found that this cut-off reduces too much the low frequency spectrum in the range $0.2<f<0.4 \mathrm{~Hz}$. Therefore the wavenumber cut-off was increased from $10 k_{p}$ to $100 k_{p}$. The directional spreading used is given by eq. 57 in Elfouhaily et al. (1997).

Resulting values of $U_{\text {ss }}$ are shown in fig. 6 and compared to the simple $f^{-5}$ extension of WWATCH ('WW3 $+f^{-5}$ '). $U_{\text {mathrmss }}$ differ by less than $10 \%$ between the three different spectra.

\section{1 .4 Results}

The ratio $U_{\mathrm{ss}} / U_{10}$ of the Stokes drift (including the analytical extension) to the wind speed is shown in fig. 8. This ratio is fairly stable, with an annual mean that varies from 0.8 to $1.5 \%$. Maximum values are in areas of large wind speeds and/or where waves are fully developed (under the trade winds).

The variability of the ratio $U_{s s} / U_{10}$ is illustrated in fig. 7 . Values larger than $1.5 \%$ correspond to a rapid decrease of the wind while the sea state remains developed. 

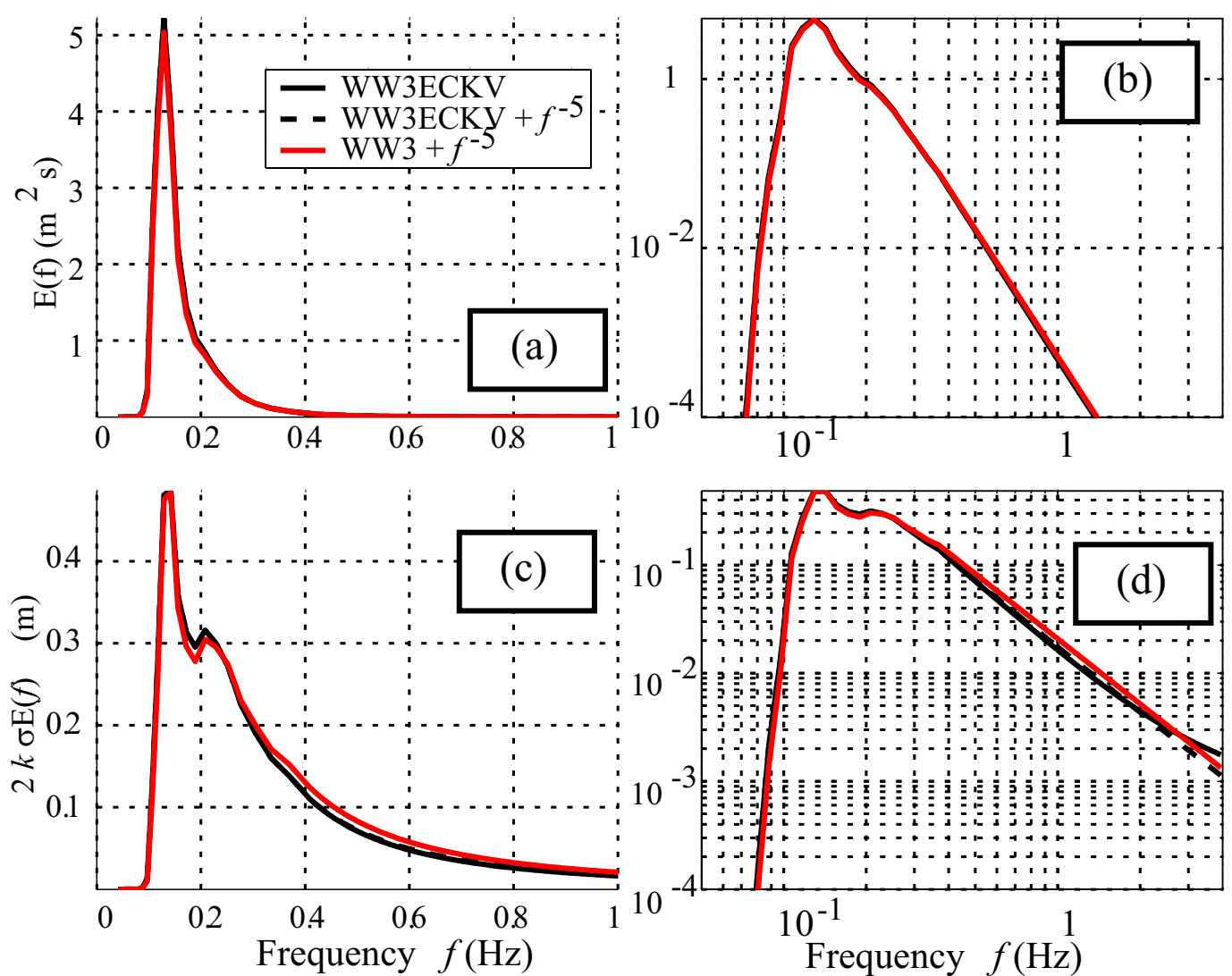

Fig. 6. (a) and (b) Omnidirectional spectrum $E(f)=\int E(f, \theta) \mathrm{d} \theta$. (c) and (d) omnidirectional spectrum of the third spectral moment $2 / g \int \sigma^{3} \cos (\theta) E(f, \theta) \mathrm{d} \theta$, as function of the frequency (this is the spectrum of $U_{\mathrm{ss}}$ in the case of unidirectional waves). Left panels are linear plots while rights panels are log-log plots. Three different spectra are used: the WWATCH spectrum extended with an $f^{-5}$ tail ('WW3 $+f^{-5}$, red line), our composite spectrum connecting WWATCH to a high frequency tail as in Elfouhaily et al. (1997) ('WW3ECKV', solid black line) and our composite spectrum cut at $f_{\max }=0.4 \mathrm{~Hz}$, and extended with a $f^{-5}$ tail ('WW3ECKV $+f^{-5}$, dashed black line). In the particular realization shown, the wind is set to $U_{10}=10 \mathrm{~m} \mathrm{~s}^{-1}$ and the waves are fully developed. $U_{\mathrm{ss}}$ reaches $12.2 \mathrm{~cm} \mathrm{~s}^{-1}$ with 'WW3 $+f^{-5}$ ' whereas it reaches $11.5 \mathrm{~cm} \mathrm{~s}^{-1}$ with 'WW3ETKV' and 'WW3ETKV $+f^{-5}$.

\subsection{The Stokes transport $T_{S}$}

The Stokes volume transport $T_{S}$ is the vertical integral of the Stokes drift $U_{s}$. Assuming a that the wave field is always fully developed, McWilliams and Restrepo (1999) and Polton et al. (2005) estimated that the mean value of $T_{S}$ could be as large as $40 \%$ of the corresponding Ekman transport $T_{E}$, depending on the latitude. Rascle et al. (2006) reevaluated this ratio using the wave spectral shape given by Kudrvavtsev et al. (1999) which yields smaller values, around $30 \%$ at most for $45^{\circ}$ of latitude. The ratio was shown to reach maximum values 


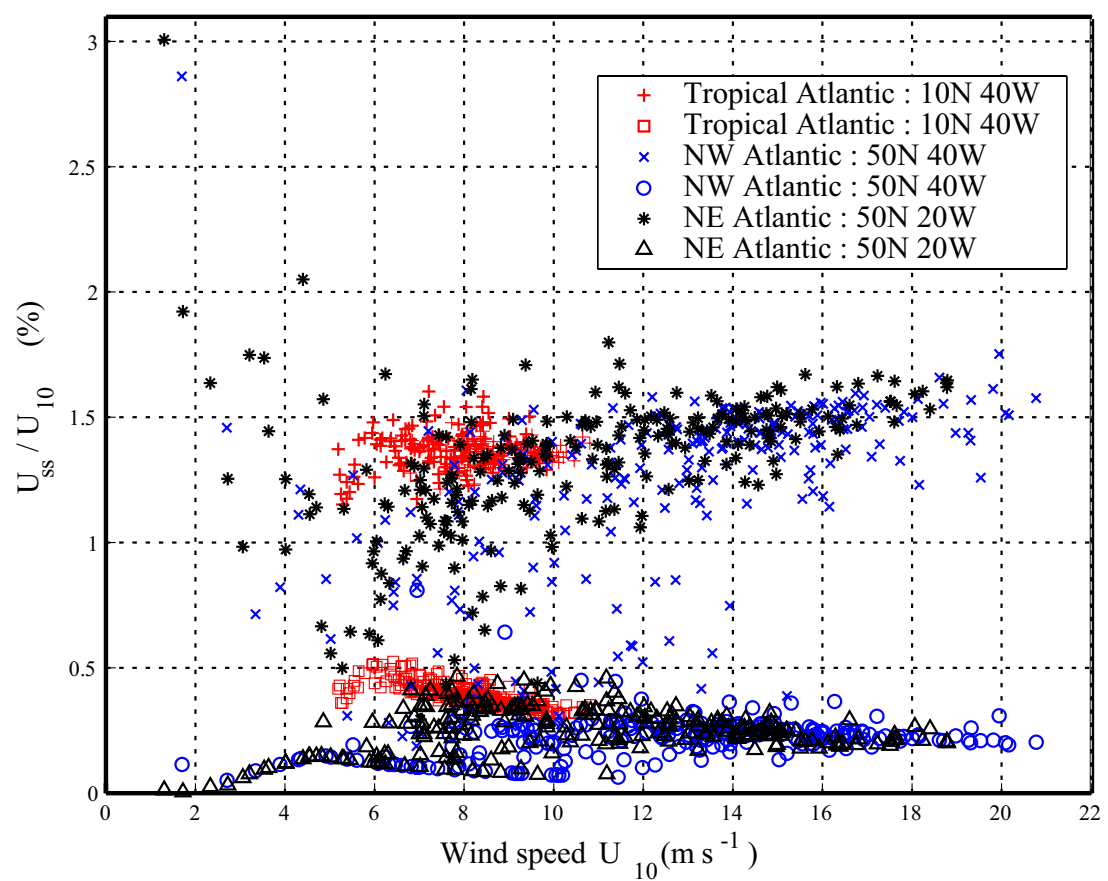

Fig. 7. Ratio of the surface Stokes drift $U_{s s}$ to the wind speed $U_{10}$ at $10 \mathrm{~m}$, in percentage, as function of the wind speed $U_{10}$, at three locations. Each symbol corresponds to one wave model output, every 3 hours, for January 2004. Symbols $\star,+$ and $\times$ denote the full Stokes drift $U_{s s}$ while the open symboles denote the contribution of the high frequency extension to the Stokes drift $U_{\mathrm{sS}}^{+}$.

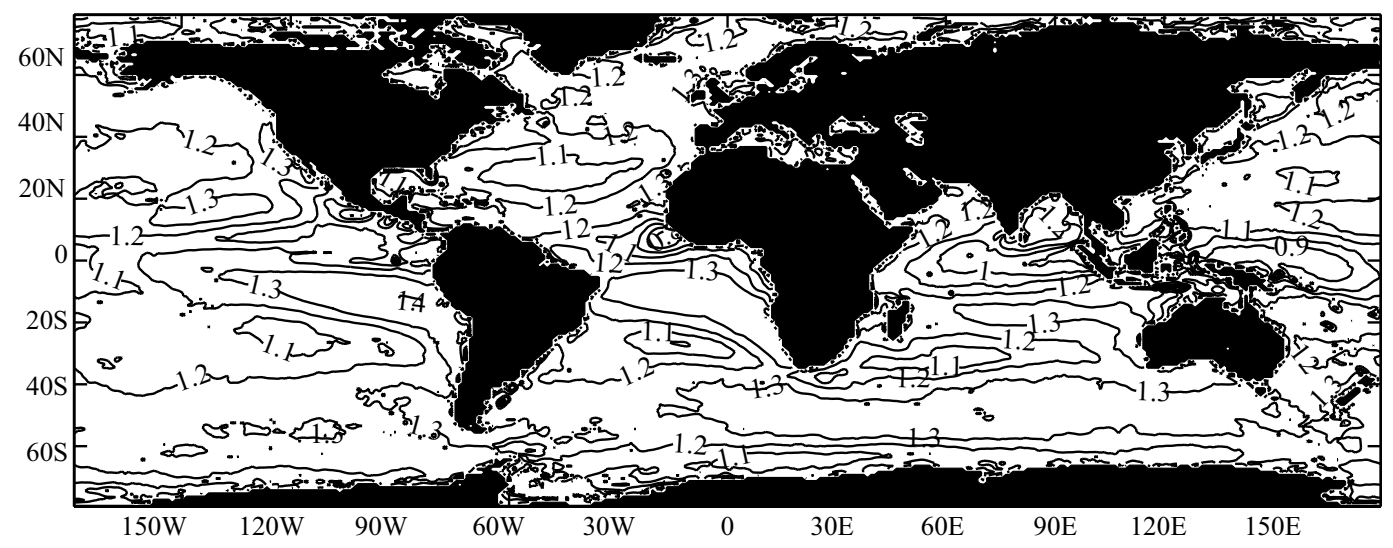

Fig. 8. mean values of the ratio of the surface Stokes drift $\left\langle U_{\mathrm{ss}} / U_{10}\right\rangle$, over the year 2004, in percentage. Contours are every $0.1 \%$.

for high wind speeds. However, waves are never fully developed for large wind speeds. Therefore we evaluate here the Stokes and Ekman transport from the wave model results. The wind stresses are predicted by the model and are consistent with the results discussed by Bidlot et al. (2007a) using the same parameterizations, and thus consistent with observations. The Stokes transport, being essentially a function of $H_{s}$ and the mean period $T_{\mathrm{m} 01}$ should be within $30 \%$ of real values given the wave model errors on $H_{s}, T_{\mathrm{m} 02}$ and $T_{p}$. The 
present estimates are likely more accurate than those of Janssen et al. (2004) who used an earlier parameterization that was giving a large positive bias on the mean period $T_{\mathrm{m} 02}$, and a $15 \%$ bias on first spectral moment $H_{s}^{2} /\left(16 T_{\mathrm{m} 01}\right)$, which would equal the Stokes transport if all the waves propagated in the same direction.

For fully developed windseas, $T_{S}$ can indeed be as large as $20-35 \%$ of $T_{E}$ for moderate to high wind speeds, respectively. In areas with high swells, $T_{S}$ can actually be of the order of $T_{E}$ on average, but these areas cover a very small part of the world ocean (figure 9). As a result, it is expected that the StokesCoriolis force should have a significant effect on the mixed layer dynamics in these areas, while it is generally weaker over most regions, especially on the western part of the ocean basins (see also Rascle, 2007, figure 3.9, for a reanalysis of the LOTUS field experiment).

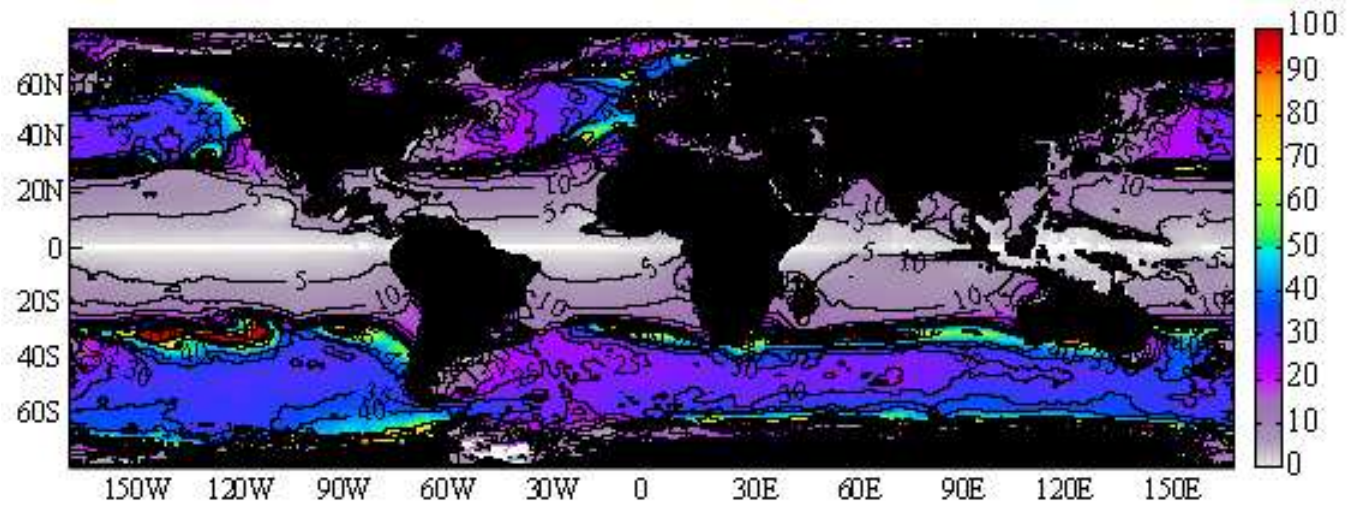

Fig. 9. Ratio of the Stokes transport $T_{S}$ to the Ekman transport $T_{E}=w_{\star}^{2} / f$, in percentage. Values shown are ratios of the mean $\left\langle T_{S}\right\rangle /\left\langle T_{E}\right\rangle$, over the year 2004, where averages are vector averages. Contours are every $5 \%$ up to $40 \%$ and every $20 \%$ above.

\subsection{The roughness length $z_{0}$}

\subsubsection{Values of $z_{0}$ and global estimations}

The roughness length $z_{0}$ is physically understood as the scale of the breaking waves and related eddies that are responsible for the high mixing levels close to the surface (Kitaigorodskii,, 1994; (Melville et al., 2002). It has been shown by Craig and Banner (1994) and by Mellor and Blumberg (2004) that this length scale is more important in terms of mixing than the amount of TKE injected by breaking waves. That length scale has been related to the significant wave height $H_{s}$ (Terrav et al., 1996). Terrav et al. (2000) proposed that

$$
z_{0}=1.6 H_{s}
$$


and verified that it was consistent with their Eulerian measurements (see also Rascle et al., 2006). Given that swells (waves not related to the local wind) generally have small orbital velocities compared to their phase speeds, they do not break (Miche, 1944). Wave at the spectral peak in fully developed conditions also break very infrequently (Banner et al., 2000). We may thus replace $H_{s}$ by the significant wave height of the wind-generated waves only $\left(H_{\mathrm{swg}}\right)$. This separation is performed in the wave spectrum based on the sign of the wind generation function, namely

$$
H_{\mathrm{swg}}=4\left(\int_{S_{i n}(k)>0} E(k) \mathrm{d} k\right)^{1 / 2}
$$

where $E(k)$ is the variance of the surface elevation for a given wavenumber $k$ and $S_{i n}$ is the energy input term in the wave energy equation. For developed waves a large fraction of the energy corresponds to waves propagating slightly faster than the wind and for which $S_{i n} \leq 0$. Our definition (6) thus yields a smaller height than the usual windsea partition $H_{\text {sws }}$ based on the analysis of local maxima in the spectrum(e.g. Hanson and Phillips, 2001). As a consequence, for a young wind-sea without swell, $H_{\text {swg }}=H_{s}$, whereas for a fully-developed wind sea, $H_{\text {swg }}<H_{s}$, the difference being typically of the order of 10 to $20 \%$. Using $H_{\mathrm{swo}}$ instead of $H_{s}$ or $H_{\mathrm{sws}}$ is also consistent with the estimate $z_{0} / H_{s} \simeq 0.6$ by Soloviev and Lukas (2003) based on measurements in tropical sea states, for mature waves. One should be aware of a remaining discrepancy with the data of Gemmrich and Farmen (2004) who rather suggest $z_{0} / H_{s} \simeq 0.25$. The difference in these estimates is possibly due to variations in the method of averaging, Eulerian in the case of Terrav et al. (1996), and surface following in the case of Gemmrich and Farmer (2004).

From a mixing perspective, $H_{\text {swg }}$ gives a scale of the minimum mixed layer depth (MLD), and thus the extremes of $H_{\text {swg }}$ should be more closely related to the MLD than the mean. These maxima are largely controlled by extreme events, in particular tropical and extra-tropical cyclones. The tracks of several storms, including hurricane Ivan in the Gulf of Mexico, are clearly visible in figure 10.b, whereas they do not appear in the mean values. It should be noted that the resolution of the present global model is insufficient to properly resolve the wind and wave fields of tropical cyclones. In the case of hurricane Ivan, the maximum value of $H_{s}$ given by the $1^{\circ}$ global model is only $12.5 \mathrm{~m}$, while $15 \mathrm{~m}$ has been measured by a buoy (Wang et al., 2005).

Because many ocean circulation models use daily mean fluxes we recommend the use of daily maxima of $H_{\text {swg }}$ in such models. Of course, since this parameter is most important for the diurnal cycle, it would be logical to also use a higher frequency forcing. 

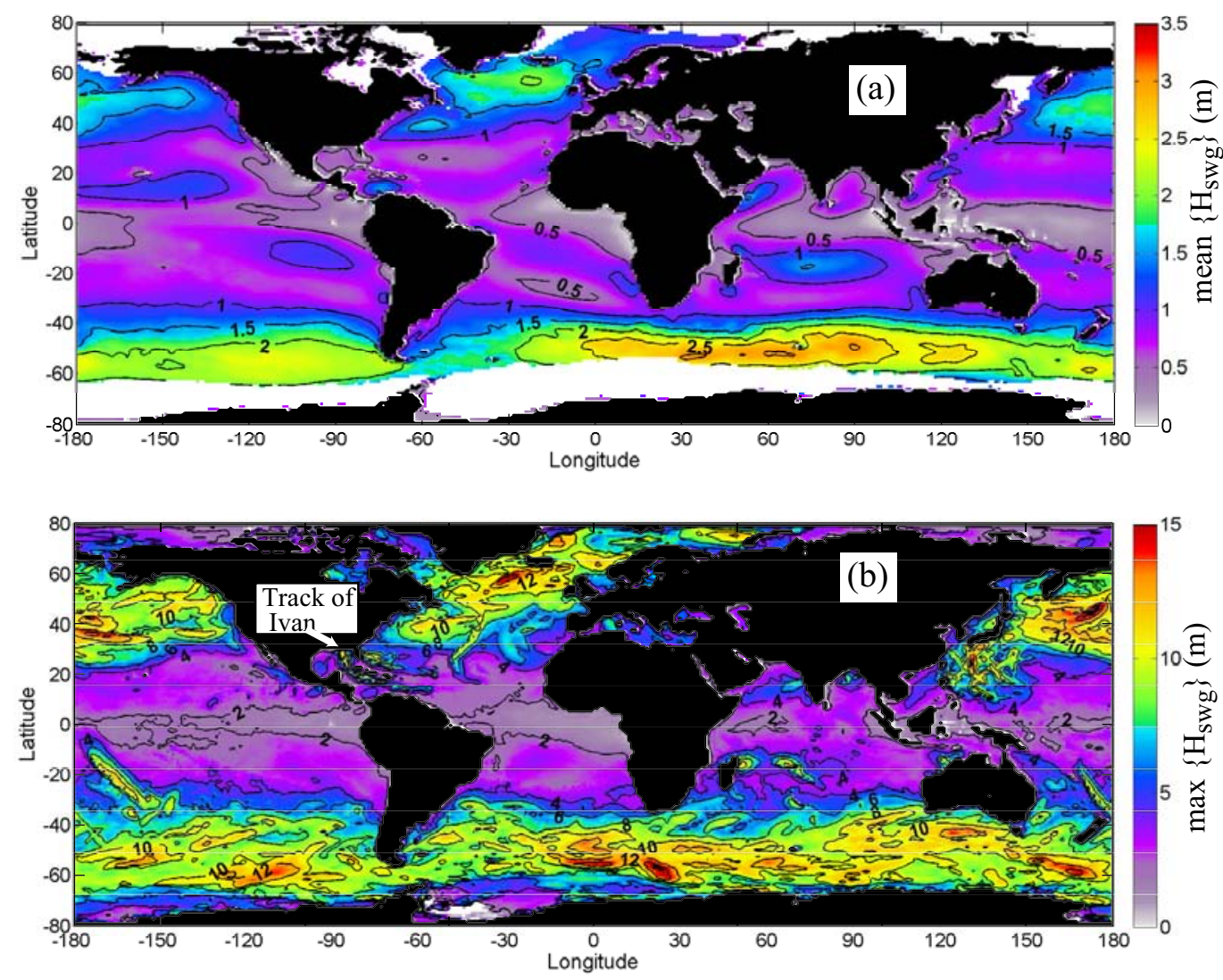

Fig. 10. Significant wave height of the wind sea, $H_{\mathrm{swg}}(\mathrm{m})$, as estimated from the wave model using eq. (6). Values shown are (a) mean values of $H_{\text {swg }}$ over the year 2004 (contours every $0.5 \mathrm{~m}$ ), and (b) maximum values of $H_{\mathrm{swg}}$ over the same year (contours every $2 \mathrm{~m}$ ).

\subsubsection{Simplistic parameterizations}

Mellor and Blumberg (2004) have related the roughness length $z_{0}$ to the friction velocity $u_{\star}$, using an approximate equation for the height of the waves as a function of the wind stress,

$$
\begin{aligned}
H_{s} & =\frac{\beta}{0.85} \frac{w_{\star}^{2}}{g}, \\
\beta & =665\left(\frac{C_{p}}{u_{\star}}\right)^{1.5},
\end{aligned}
$$

where $C_{p} / u_{\star}$ is the wave age, i.e. the ratio of the phase speed of the dominant waves to the atmospheric friction velocity. $w_{\star}$ is the waterside friction velocity, related to the atmospheric friction velocity with 


$$
r=\frac{w_{\star}}{u_{\star}}=\left(\rho_{a} / \rho_{w}\right)^{1 / 2} \simeq 1 / 28
$$

where $\rho_{a}$ and $\rho_{w}$ are the density of air and water, respectively.

Note that Mellor and Blumberg (2004) did use the definition of the mixing length $l=\kappa \max \left(z_{0}^{\prime},|z|\right)$, with the corresponding roughness length $z_{0}^{\prime} \simeq 0.85 H_{s}$ (Terray et al., 2000), whereas we stayed with $l=\kappa\left(z_{0}+|z|\right)$ and $z_{0} \simeq 1.6 H_{s}$ as discussed in Rascle et al. (2006). Because of these different definitions of the roughness length, we will rather discuss here the values of the wave height.

For a wave age of $C_{p} / u_{\star}=30$, i.e. fully developed waves, eq. 8 gives

$$
\beta=1 \times 10^{5}
$$

Estimations of $z_{0}$ by Stacev (1999), from velocity profiles observations, gave value of $\beta$ even larger, $\beta=2 \times 10^{5}$, although the waves were quite young during their Canadian fjord measurements. Therefore Mellor and Blumberg (2004) investigated values of $\beta$ between $1 \times 10^{5}$ and $2 \times 10^{5}$.

Indeed, waves are almost never fully-developed, and the comparison of the parameterization (10) of the wind-generated wave height and the calculation from the wave model, using (6), shows a large discrepancy at mid-latitudes, while the agreement is acceptable at low latitudes (fig.11).

The wave age $C_{p} / u_{\star}$ is obviously missing in a direct parameterization of the wind-wave height from the wind such as eq. (10) . Waves are generally fullydeveloped under weak winds and are often quite young under strong winds (fig. 11). Although we warmly recommend using wave parameters from a wave model, we nevertheless propose here a better approximation of the wind-wave height, for those who do not want to use a wave model. This approximation supposes that the wave age is a function of the wind speed,

$$
\frac{C_{p}}{u_{\star}}=30 \tanh \left(\frac{u_{\star \mathrm{ref}}}{u_{\star}}\right)
$$

where $u_{\star \text { ref }}$ is a typical friction velocity above which the wave growth is limited by the fetch or the duration of the wind (see fig. 13, left panel). Here we set $u_{\star \mathrm{ref}}=0.6 \mathrm{~m} \mathrm{~s}^{-1}$. The wave height is then given by eq. (7) with

$$
\beta=665\left[30 \tanh \left(u_{\star \mathrm{ref}} / u_{\star}\right)\right]^{1.5} .
$$

This estimation corrects the bias in the mean significant generated wave height $<H_{\text {swg }}>$ (fig. 11). 


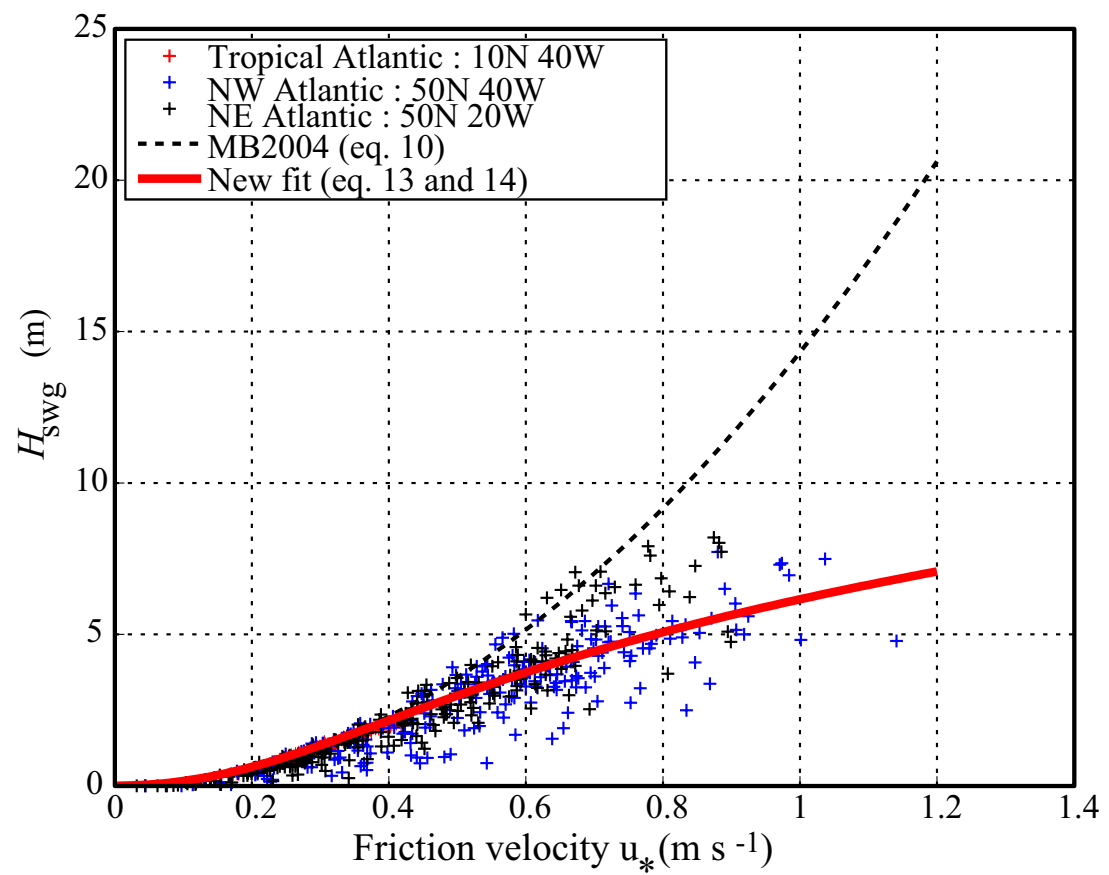

Fig. 11. Significant wave height of the generated seas $H_{s w g}$ as a function of the air-side friction velocity $u_{\star}$. Each symbol corresponds to one wave model output, every 3 hours, for January 2004. Three locations of the North Atlantic are shown, one from the Tropical Atlantic, one from the North-East Atlantic and one from the North-West Atlantic. Also shown is the significant wave height of the wind sea as inferred from (10), which supposes full development. At low wind speed, the waves are often close to full development. However, for large wind speeds at mid-latitudes, waves are less developed, especially in the west part of the oceans. Therefore, we also show the significant wave height obtained by supposing that the wave age is a function of the wind speed via (11) and (12).

If one is interested in the average wave-induced mixing, we propose the use of the formula (12) to roughly parameterize the wave-breaking effect on the mixing, for instance for application to an OGCM. The formulae (10), using maximum values of $u_{\star}$, remain useful to given an upper bound for the waveinduced mixing.

The next step to built a more accurate simple formula could be to suppose that the wave age is a function of both wind speed and position, $C_{p} / U_{10}=$ $f\left(U_{10}, x, y\right)$. This would lead us to build a climatology of wave ages, and could roughly represent the young sea states in the west parts of the oceans, due to the fetch limited growth of the waves.

However, the use of a wave model in addition to the ocean circulation model is by far preferable to such simple climatological parameters because the spatial and temporal variability of extreme events with larger waves would be better represented. 


\subsection{Fluxes of turbulent kinetic energy}

\subsubsection{Previous estimates of $\Phi_{\mathrm{oc}}$}

As waves break they give up part of their momentum $M^{w}=\rho_{w} T_{S}$ and energy $E=\rho_{w} g H_{s}^{2} / 16$, to the mean current and turbulence, respectively. Because the ratio of the losses of momentum and energy is the phase speed of the breaking wave, while the corresponding ratio for the current is the generally much smaller current velocity, one may neglect the gain of kinetic energy by the current and consider that all the wave energy lost by breaking is converted to TKE. Indeed the mean phase velocity of breaking waves $\bar{C}$ was estimated between 5 and $12 \%$ of $U_{10}$ by Gemmrich et al. (1994), while the wind driven current is typically of the order of $0.5 \%$ of $U_{10}$ at large scales (Rascle et al., 2006). Janssen et al. (2004) gave a mean value $\bar{C}=5.2 u_{\star} \simeq 0.15 U_{10}$, with large regional fluctuations. That latter estimation was performed with a numerical wave model, an approach that we follow here. Preliminary calculation reported in Rascle (2007) were up to a factor of two larger due to a numerical error.

Due to the variability of the wave field, it is convenient to normalize the flux $\Phi_{\mathrm{oc}}$ by the air density $\rho_{a}$ and air-side friction velocity $u_{\star}$, or the water density $\rho_{w}$ and water-side friction velocity $w_{\star}=r u_{\star}$. In that latter form, $\Phi_{o c}=\rho_{w} \alpha_{\mathrm{CB}} w_{\star}^{3}$ is determined by the Craig and Banner (1994) parameter $\alpha_{\mathrm{CB}}$. An estimation of $\alpha_{\mathrm{CB}}$ is very difficult because most of the TKE generated by the waves is dissipated very near the surface, where measurements are made extremely difficult due to the moving surface and the presence of bubbles entrained by breaking waves (e.g. Gemmrich and Farmer, 2004). Because the atmosphere to wave energy flux $\Phi_{a w}$ should be within a few percent of $\Phi_{\text {oc }}$ (Donelan, 1999; Janssen et al., 2004), it is convenient to use the better known $\Phi_{\text {aw }}$ and its spectral distribution. Terrav et al. (1996) calculated $\Phi_{\mathrm{oc}}$ using empirical expressions for the energy input from wind to waves, $S_{i n}(f, \theta)$, given by Donelan and Pierson (1987), and integrated over a large variety of observed wave energy spectra to give $\Phi_{\mathrm{aw}} \simeq \Phi_{\mathrm{oc}}$. They obtained values of $\alpha_{\mathrm{CB}}$ between 50 and 150, depending on the wave age (Terrav et al., 1996, figure 8). The monthly mean estimate $0<\bar{C} / u_{\star}<6$ by Janssen et al. (2004, figure 14 ) for most regions of the world ocean, is consistent with $0<\alpha_{\mathrm{CB}}<170$ because

$$
\alpha_{\mathrm{oc}}=\bar{C} / u_{\star}=r \alpha_{\mathrm{CB}} .
$$

Nevertheless, it should be noted that the wind-wave growth term of Donelan and Pierson (1987) was later revised by Donelan (1990), with the dimensionless growth factor increased from 0.19 to 0.28 . We thus expect such a proportional increase to apply to the $\Phi_{o c}$ estimated by Terrav et al. (1996). 


\subsubsection{Values of $\Phi_{\mathrm{oc}}$ and global atmosphere-ocean energy fluxes}

The growth factor used by Janssen et al. (2004) and in the present paper is a function of the wave age and wave-supported stress. Our best estimate of the monthly mean values of $\alpha_{\mathrm{CB}}$ is generally consistent with the results of Janssen et al. (2004). Minor differences are likely due to a different parameterization of the dissipation and definition of the prognostic range in the wave model, as changed by Bidlot et al. (2005), and our use of a larger frequency range, with $f_{\max }=0.7 \mathrm{~Hz}$. In particular our estimates of $u_{\star}$, are identical to those of Bidlot et al. (2005). The present values of $u_{\star}$ agree with the relatively young waves measured during HEXOS (Bidlot et al., 2007a), but careful and more general validation of $u_{\star}$ is needed, as was done by Bonekamp et al. (2002) with the old version of ECWAM.

It is suspected that $u_{\star}$ is still overestimated for $U_{10}>25 \mathrm{~m} \mathrm{~s}^{-1}$. Simulations of the 2004 hurricane Ivan with the present model ran at a resolution of $0.1^{\circ}$ and using wind fields from NOAA's Hurricane Research Division (Powell and Houston, 1998) produces drag coefficients $C_{d} u_{\star}^{2} / U_{10}$ that can be as large as 0.004, while field observations and inverse ocean modelling suggest maximum values between 0.002 and 0.003 (Powell et al., 2003; Jarosz et al., 2007). In order to evaluate the effect of this overestimation for high winds, we have corrected the fluxes $\Phi_{\text {aw }}$ and $\Phi_{\text {oc }}$ by assuming unchanged values of $\alpha_{\text {aw }}=\Phi_{\text {aw }} /\left(\rho_{a} u_{\star}^{3}\right)$, and adjusting $u_{\star}$ to limit $C_{d}$ to a maximum value of 0.002 . This correction has a very limited impact on yearly mean values.

We further find that the global mean flux of TKE from waves to the ocean is $0.20 \mathrm{~W} \mathrm{~m}^{-2}$, with mean values close to 0.05 in the tropics and up to $0.9 \mathrm{~W} \mathrm{~m}^{-2}$ at mid-latitudes. Integrated over the ocean this gives a total atmosphere to wave flux of $70 \mathrm{TW}$, out of which $2.4 \mathrm{TW}$ are radiated to the shores and 68 TW are available for ocean mixing (fig. 12). In these $68 \mathrm{TW}$, there are of the order of $\left\langle\rho_{a} u_{\star} U_{\mathrm{ss}}\right\rangle=6 \mathrm{TW}$ of TKE produced by the straining turbulence due to the Stokes drift (the actual number depends on the stratification, see Ardhuin and Jenkins, 2006), which may fuel Langmuir circulation.

The reader may compare these numbers to the much smaller numbers given by (Wunsch and Ferrari, 2003, figure 5). This energy is eventually converted to heat. Although this flux of energy is very small in the global ocean heat budget, it may still have a significant effect in long term climate simulations. More importantly this flux can locally exceed $50 \mathrm{~W} \mathrm{~m}^{-2}$, in hurricanes of category 3 and above. Because the effective phase speed $\bar{C}$ is of the order of 10 to $15 \%$ of $U_{10}$ in hurricane conditions, this dissipative heating of the ocean amounts to only 10 to $15 \%$ of the atmospheric dissipative heating discussed by Bister and Emanuel (1998). To our knowledge this term has not yet been included in coupled ocean-wave-atmosphere models of hurricanes, but given its relatively small magnitude, it is unlikely to have a major impact on hurricane 
dynamics.

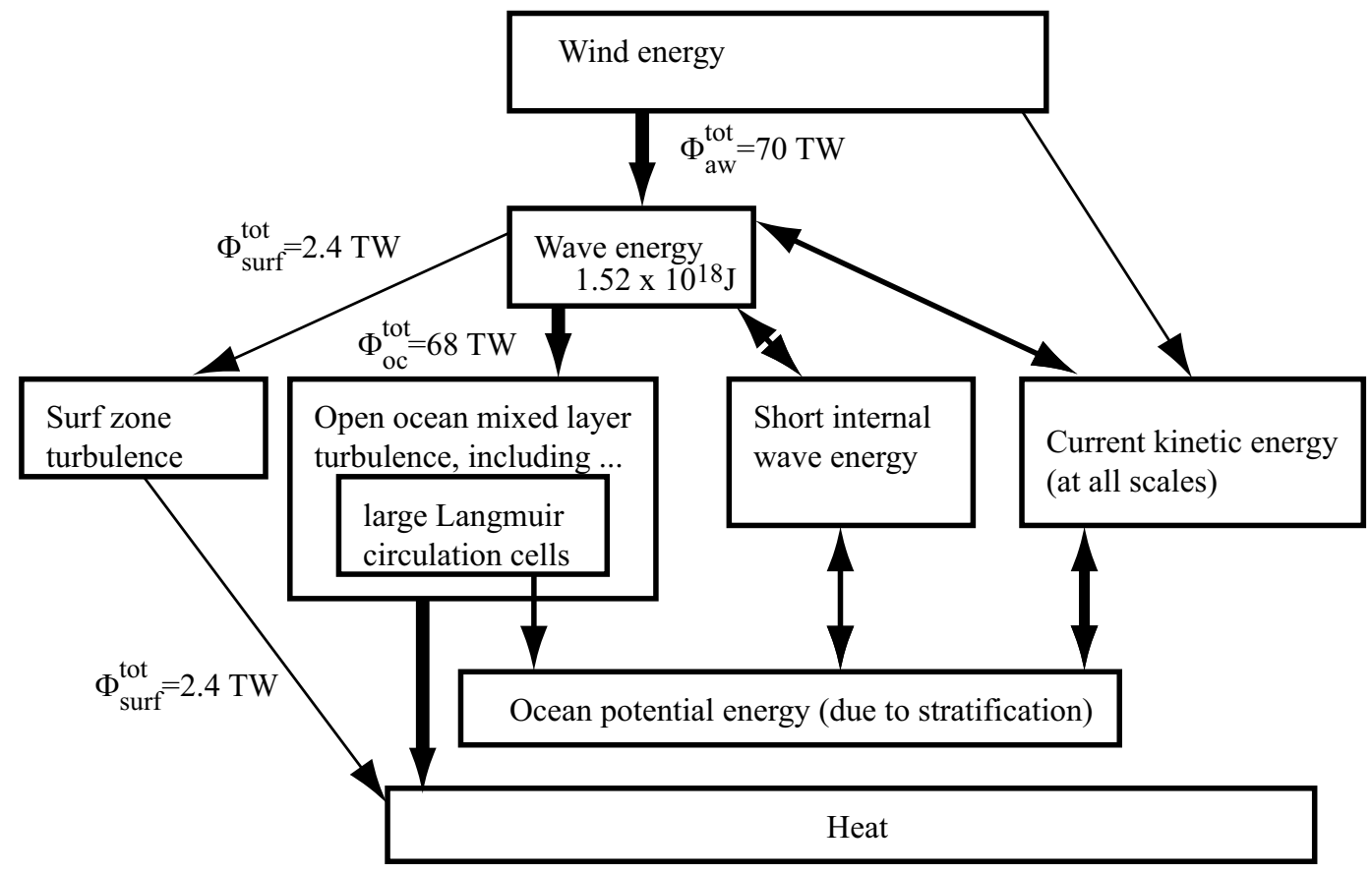

Fig. 12. Wave-related energy budget between the atmosphere and ocean.

\subsubsection{Simplistic parameterizations}

Again, we do not advise parameterizing the wave field from the wind only. However, we have experienced a certain level of allergy by ocean ciculation modellers to whatever comes out of a wave model. We thus reconsider the simplistic parameterizations of $\Phi_{o c}$. Fitting the flux data shown in Terrav et al. (1996, figure 8), Mellor and Blumberg (2004), with the expression

$$
\alpha_{C B}=15 \frac{C_{p}}{u_{\star}} \exp \left[-\left(0.04 \frac{C_{p}}{u_{\star}}\right)^{4}\right] .
$$

As that expression does not fit the WWATCH calculation very well, we propose the following correction to account for the parameterization used in WWATCH

$$
\alpha_{C B}=P\left(\frac{C_{p}}{u_{\star}}\right)
$$

$P$ is a third order polynomial to fit $\alpha_{\mathrm{CB}}$ as a function of the wave age,

$$
P(x)=-0.0135 x^{3}+0.41 x^{2}+3 x .
$$


This fit provides reasonable values compared to $\alpha_{\mathrm{CB}}$ calculated with WWATCH (figure 13.b).
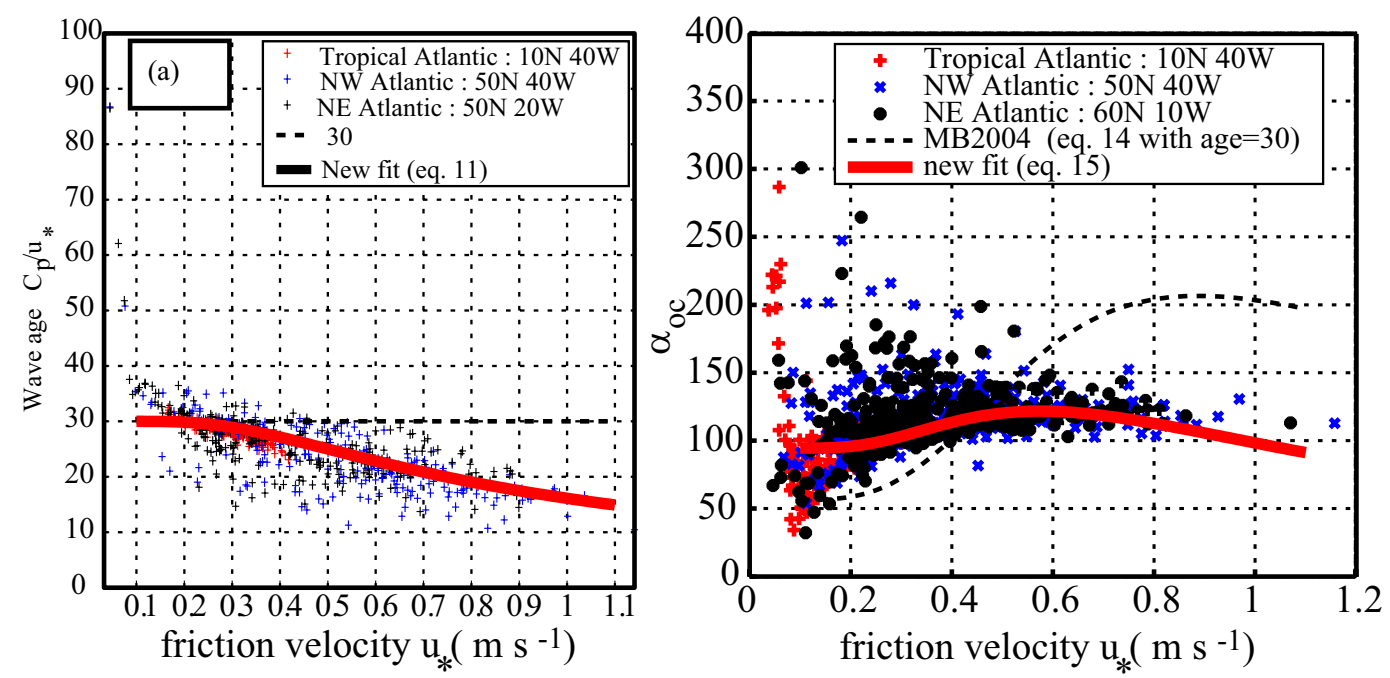

Fig. 13. (a) Wave age $C_{p} / u_{\star}$ as function of the friction velocity $u_{\star} / u_{\star}^{\text {ref }}$, from our estimation 11, for the month of January 2004. (b) Daily mean Craig-Banner parameters $<\alpha_{\mathrm{oc}}>_{1 \text { day }}=<\Phi_{o c}>_{1}$ day $/\left(<u_{\star}^{2}>_{1} \text { day }\right)^{3 / 2}$, as a function of the waterside friction velocity $u_{\star}$, for the entire year 2004. The 1 day subscript means that the average is taken over one day. Each symbol thus corresponds to a one-day average using the cumulated energy flux and momentum flux. Three locations of the North Atlantic are shown, one from the Tropical Atlantic, one from the North-East Atlantic and one from the North-West Atlantic. Also shown are the parameter $\alpha_{\text {oc }}$ calculated by supposing that the wave age is a function of the wind speed (eq. 11), and that $\alpha_{C B}$ is a function of the wave age according to Mellor and Blumberg (2004) (eq. 14, dashed line) or a function of both the wave age and the wind speed according to our corrected formulation (eq. 15, solid lines).

Janssen et al. (2004) further highlighted the spatial distribution of the parameter $\alpha_{C B}$, which exhibits a strong latitude dependency, because the wave field is often less developed at mid-latitudes (see their fig. 14). Our result show the same pattern but with a weaker gradient, probably due to the fact that we take into account the shorter waves $\left(f_{\max }=0.7 \mathrm{~Hz}\right.$ instead of $\left.0.4 \mathrm{~Hz}\right)$ that dominate the tropical wind seas and were absent in that earlier work. Once again, the wave age is often correlated with the wind stress, leading to a correlation between the parameter $\alpha_{\mathrm{oc}}$ and the wind stress (fig.13.a). Rather than supposing the parameter $\alpha_{\mathrm{oc}}$ constant, a simple parameterization of $\alpha_{\mathrm{oc}}$ as a function of the wind stress would be more accurate. Of course, we again insist that using a wave model to derive these parameters would be better, since such an empirical fit cannot reproduce the full variability due to the wave field. If, as in the previous section, if one supposes that the wave-age depends on the wind stress via (11), then one could use (14) to estimate $\alpha_{\mathrm{oc}}$ directly from the wind stress. It is shown in fig. 13.b that such an estimation yields a reasonable trend but largely overestimates $\alpha_{\text {oc }}$. On the contrary our corrected 
formulation (15) fits the WWATCH calculations reasonably well (fig. 13.b).

\section{Impact of the wave-related parameters on the mixed layer depth}

In this section we perform a sensitivity study of the impact of the previously discussed parameters on the mixed layer depth. We use the simple one-dimensional Mellor-Yamada type model of Noh (1996). In the absence

of stratification, this model is equivalent to the model of Craig and Banner (1994), which takes into account the wave-induced near surface mixing with a surface flux of TKE $\Phi_{\mathrm{oc}}$ and with a large roughness length $z_{0}$. The model of Noh (1996) extends to stratified conditions in a way similar to the model of Gaspar et al. (1990), the main common feature being that the roughness length $l$ is bounded by the buoyant length scale $l_{b}\left(=q / N\right.$, where $q^{2} / 2$ is the TKE and $N$ is the Brunt-Väisälä frequency) when the stratification gets strong. The main difference with the model of Mellor and Yamada (1982) is that the flux Richardson number is replaced by a turbulent Richardson number, which is more convenient in the surface layer where the production of turbulence by the mean current shear is not the dominant source of TKE (Noh, 1996; Mellor, 2003).

The model of Noh (1996) was run with a time step $d t=10 \mathrm{~s}$. It is shown in fig. 14 that the mixed layer depth obtained with this model in the presence of both wind- and wave-induced mixing and a stabilizing buoyancy flux strongly depends on the sea state parameters. Also, in a case without buoyancy flux, the rate of thermocline erosion by the wind- and wave-induced mixing depends on the sea state parameters.

This sensitivity study confirms that the near-surface mixing and the mixed layer depth critically depends on the sea state parameters $z_{0}$ and $\Phi_{o c}$. This result is unambiguous for shallow mixed layers. An estimation of the depths reached by the downward flux of the TKE is around a few times $z_{0}$ (see Craig and Banner, 1994, their eq. 27). The downward flux of TKE due to surface waves is thus expected to be important for depths of the order of a few tens of meters, in particular in the presence of neutral or stabilizing buoyancy fluxes, such as in the Arabian Sea or the Southern Ocean during the southern hemisphere summer.

At greater depths, other processes might dominate the mixing. Some of them are related to the sea state, like the Langmuir circulation, while other phenomena are not, as are the current shear at the thermocline due to inertial oscillations (Li et al., 1995) or the internal waves. The impact of surface waves on the mixing at greater depth is then more difficult to highlight, as it could be hidden by other phenomena. Also, more sophisticated models are needed 


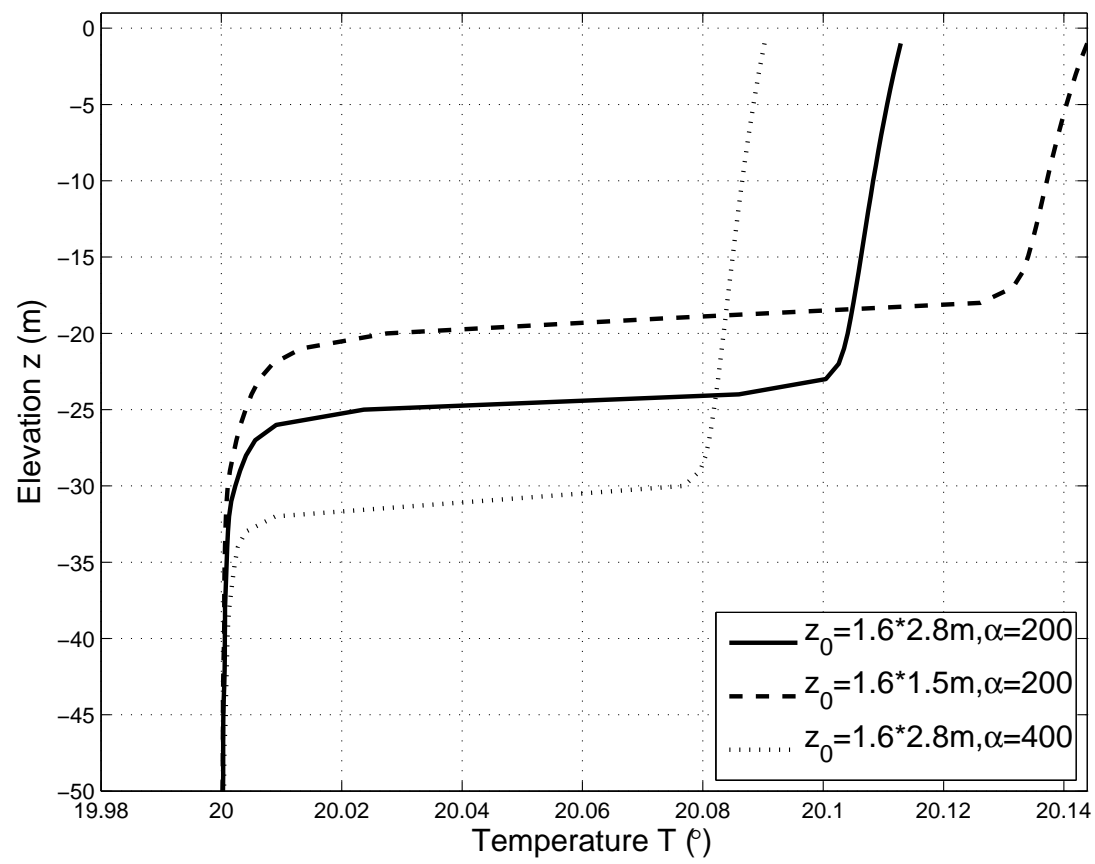

Fig. 14. Impact of the wave development on the diurnal mixed layer depth, as inferred from a simple TKE model (Noh, 1996; Noh and Kim, 1999). The temperature profile is calculated from an initially uniform temperature of $T=20^{\circ} \mathrm{C}$, after 6 hours of stabilizing buoyancy flux of $500 \mathrm{Wm}^{-2}$ and of mixing due to a wind of $10 \mathrm{~ms}^{-1}$ and its associated wind sea. Solid line is for fully developed waves $\left(H_{s}=2.8 \mathrm{~m}\right)$ while dashed line is for a limiting fetch of $100 \mathrm{~km}\left(H_{s}=1.5 \mathrm{~m}\right)$. Those are typical on a continental shelf during onshore and offshore wind events. More developed waves provide more intense near-surface mixing, which creates a deeper diurnal mixed layer. Also shown is the impact of variations of the TKE flux : dotted line is with a parameter $\alpha$ twice as large.

to compare the intensity and the depths those different sources of mixing can reach.

Similarly, the TKE dissipation measurements used to build simple TKE models of the near-surface wave-induced mixing where made at quite shallow depths (e.g. Terrav et al., 2000). Extension of these results to greater depths must be checked with other measurements.

\section{Conclusion}

Ocean surface mixing and drift is a function of the surface Stokes drift, $U_{\text {ss }}$, volume Stokes transport $T_{S}$, a wave breaking height scale $H_{\text {swg }}$, and the flux of energy from waves to ocean turbulent kinetic energy $\Phi_{\text {oc }}$. Here we describe a global database of these parameters that covers the years 2004 to 2007, 


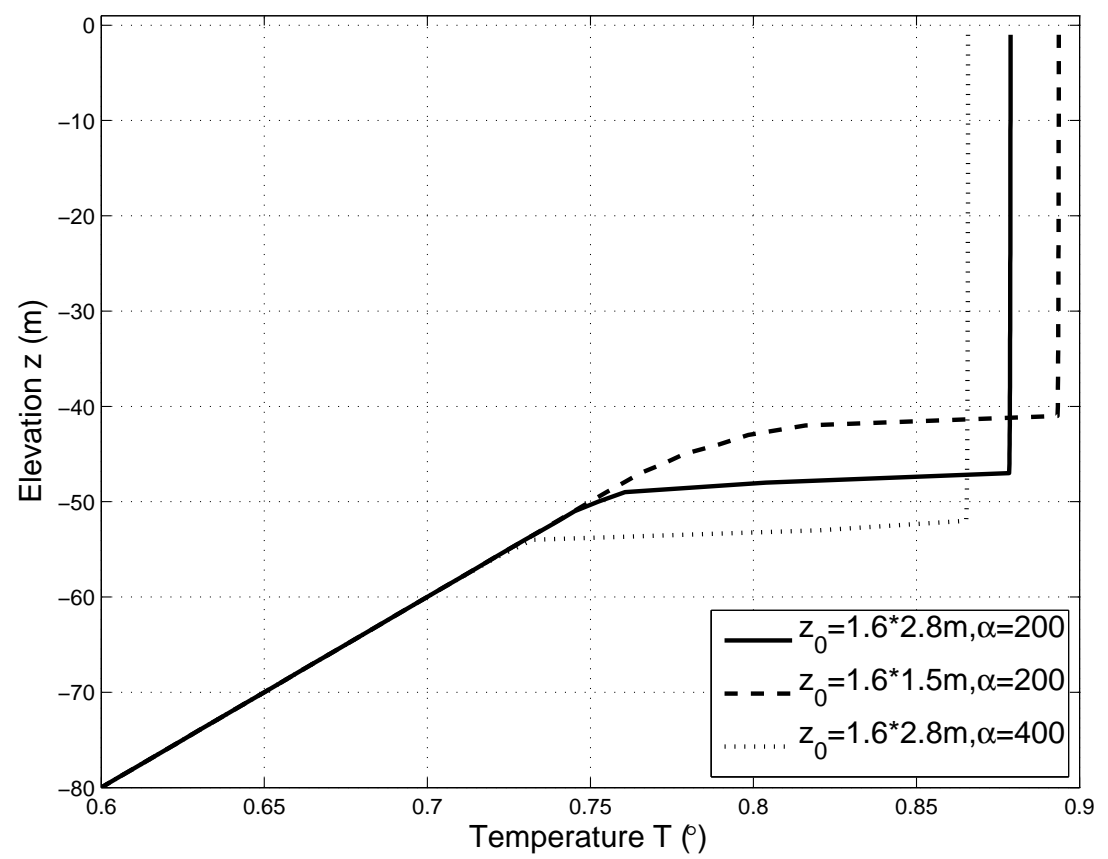

Fig. 15. Impact of the wave development on the deepening of the mixed layer. The initial temperature is calculated from an initial profile $T=1+0.005 z$, where $z \leq 0$, after 120 hours of erosion of the stratification without any buoyancy flux but of with mixing due to a wind of $10 \mathrm{~ms}^{-1}$ and its associated wind sea. Solid line is for fully developed waves $\left(H_{s}=2.8 \mathrm{~m}\right)$ while dashed line is for a limiting fetch of $100 \mathrm{~km}$ $\left(H_{s}=1.5 \mathrm{~m}\right)$. Also shown is the impact of variations of the TKE flux : dotted line is with a parameter $\alpha$ twice as large. It is shown that the different stages of wave development may have an impact on the thermocline erosion : more intense mixing provides faster erosion.

estimated from a well-validated numerical wave model. Compared to previous estimates of these parameters, the present work has the advantage of being consistent with the know physical processes that regulate the wave field and the air-sea fluxes, and also consistent with a very large number of observations of wave parameters using in situ measurements and satellite remote sensing.

Our estimates may differ by more that one order of magnitude from previous estimates. In particular, we find that the global TKE flux $\Phi_{\mathrm{oc}}$ is $68 \mathrm{TW}$ and the mean Stokes volume transport, is typically of the order of $30 \%$ of the Ekman transport, with values larger on the Eastern part of ocean basins, and very strong values in areas with large swells, just outside of the mid-latitudes storm tracks. We also have refined our previous estimates of the surface Stokes drift $U_{\mathrm{ss}}$ by using a better treatment of the implicit high frequency part of the wave spectrum. In the open ocean, $U_{\mathrm{ss}}$ is of the order of $1.5 \%$ of the wind speed $U_{10}$.

The present database will be updated as soon as an acceptable parameterization is found that takes into account the damping of waves by the wind. At 


\begin{tabular}{ccccc}
\hline Variable & components & units & range of values & file extension \\
\hline$H_{s}$ & 1 & $\mathrm{~m}$ & 0 to 99 & .hs \\
$f_{p}$ & 1 & $\mathrm{~s}^{-1}$ & 0 to 1 & .fp \\
$H_{\mathrm{swg}}$ & 1 & $\mathrm{~m}$ & 0 to 99 & .hsw \\
$f_{\mathrm{pwg}}$ & 1 & $\mathrm{~s}^{-1}$ & 0 to 1 & .f ws \\
$\alpha_{\mathrm{aw}}$ & 1 & without dimensions & 0 to 999 & .paw \\
$\alpha_{\mathrm{oc}}$ & 1 & without dimensions & 0 to 999 & .poc \\
$U_{\mathrm{ss}}$ & 2 & $\mathrm{~m} \mathrm{~s}^{-1}$ & 0 to 1 & .uss \\
$u_{\star}$ & 2 & $\mathrm{~m} \mathrm{~s}^{-1}$ & 0 to 5 & .ust \\
$T_{S}$ & 2 & $\mathrm{~m}^{2} \mathrm{~s}^{-1}$ & 0 to 1 & .tus \\
\hline
\end{tabular}

Table A.1

Gridded parameters archived in the database. All parameters are described in the text except $f_{\mathrm{pwg}}$ which is the mean period $T_{\mathrm{m} 0-1}$ of the part of the spectrum which receives energy from the wind (i.e. where $\left.S_{i n}>0\right)$ ). $f_{\text {pwg }}$ was used to define the age of the wind sea in figure 13.

present the model is known to overestimate swell heights, which should have a minimal impact on the air-sea flux parameters, and understimate wind sea wave heights, except at high winds.

Finally, the database will be extended to include other wave-related parameters of interest to other geophysical applications. These include momentum fluxes in and out of the wave field to allow a modelling of the full wave-current coupling (Ardhuin et al., 2008), directional slope statistics for remote sensing studies, i.e. for the correction of Doppler-derived surface currents (Chapron et al., 2005), surface salinity or altimeter sea state bias(e.g. Feng et al., 2006), and microseism generation forces.

\section{A Database variables, formats and organization}

Two types of variables have been computed and stored. The first are spectra at preselected locations (buoys and other places of interest). The second are scalar (or 2 component vector) variables. These may be estimated from the output spectra ('bulk' variables such as $H_{s}, f_{p} \ldots$ ), or over the entire grid at run time. The gridded variables listed in table A.1 have been stored.

From the root directory on the FTP site one has access to various model domain, including the global $1^{\circ}$ domain data, described here. In this global folder, the data are organized by year, and all the necessary model input files are also provided, except for wind, ice and current forcing which are a property 
of ECMWF and Mercator.

The fluxes $\Phi_{\text {oc }}$ and $\Phi_{\text {aw }}$ in Watts per meter squared are obtained using,

$$
\begin{gathered}
\Phi_{\mathrm{oc}}=\rho_{a} \alpha_{\mathrm{oc}} u_{\star}^{3} \\
\Phi_{\mathrm{aw}}=\rho_{a} \alpha_{\mathrm{aw}} u_{\star}^{3} .
\end{gathered}
$$

Here we used $\rho_{a}=1 ? .29 \mathrm{~kg} \mathrm{~m}^{-3}$.

\section{B Validation against altimeters}

Altimeter $H_{s}$ measurements are presently available almost continuously over a 16-year time period from the six altimeter missions ERS-1, ERS-2, TOPEXPoseidon, GEOSAT Follow-ON (GFO), Jason-1 and ENVISAT . Altimeters are short pulse nadir looking radars, operating at $\mathrm{Ku}$-Band frequency (with additional measurements at C-Band frequency for TOPEX and Jason-1, and at S-Band for ENVISAT). The radar emitted pulses are reflected by the sea surface, at nadir, towards the satellite antenna. At zero incidence angle the reflection is mainly specular. The satellite return waveform is averaged over typically of the order of one thousand pulses, corresponding to a distance of 5 to $7 \mathrm{~km}$ along the ground track. From analysis and modelling of the return waveform 3 parameters are estimated: the satellite altitude over the sea surface, from which the sea surface height is deduced, the backscatter coefficient, proportional to the surface mean square slope and highly correlated with the surface wind speed, and the significant wave height. The accuracy of the $H_{s}$ retrieval is of the order of $0.50 \mathrm{~m}$ or $10 \%$, whichever is greater, for the first generation of altimeters, onboard of ERS and TOPEX, and better for more recent instruments, onboard of ENVISAT and Jason. Although the altimeter measurements are calibrated during specific commissioning phase, just after launch, long term monitoring of the performances is essential, revealing significant differences between $H_{s}$ measurements provided for the various altimeters by the dedicated space agencies. The altimeter $H_{s}$ data used in this study are issued from the IFREMER CERSAT altimeter $H_{s}$ data base. The data base is constructed using the Geophysical Data Records (GDR) for each altimeter, and correcting $H_{s}$ measurements according to previous studies. For the present wave model assessment study, data from Jason-1 (Picot et al.,, 2003), GEOSAT Follow-On (Naval Oceanographic Office and NOAA Laboratory for Satellite Altimetrv, 2002), and ENVISAT (ESA, 2002) were used. The linear corrections to be applied to the altimeter SWH GDR are given as slope and intercept coefficients in table B.1. The Jason GDR version b correction was estimated from comparison with 7193 collocated buoy measurements. ENVISAT and GFO corrections resulted from previous investigations (Queffeulou, 2004, 2006). 
Table B.1

\begin{tabular}{ccc}
\hline Altimeter & slope & intercept \\
\hline Jason & 1.0250 & 0.0588 \\
GFO & 1.0625 & 0.0754 \\
ENVISAT & 1.0585 & -0.1935 \\
\hline
\end{tabular}

Correction parameters for altimeter data

Data from the altimeters and from the model outputs were collocated. For each altimeter pass (half orbit about $40 \mathrm{mn}$ to $50 \mathrm{mn}$ long) the model output field which is the closest, in time, of the mean value of the satellite pass time, is selected. Thus the maximum value of the time difference between model and altimeter data is $1 \mathrm{~h} 30 \mathrm{~mm}$. The model data fields are then interpolated to the altimeter measurement locations (one measurement every 5-7 km, along track).

Then, satellite and interpolated model data are averaged along the ground track over $1^{\circ}$ latitude steps. The number of data averaged over $1^{\circ}$ depends on the latitude and on the altimeter sampling. It is on average of the order of 1920 for Jason, 18-19 for GFO eand 15-16 for ENVISAT. For the analysis, only cases corresponding to a data number larger than 15 are selected for Jason and GFO, and larger than 12 for ENVISAT.

Acknowledgments. This research would not have been possible without the wind and ice fields provided by ECMWF and Meteo-France, the surface current fields provided by Mercator-Ocean (http://www.mercator-ocean.eu), the satellite altimeter data provided by ESA and CNES, and the many in situ observations acquired by all contributors to the WMO exchange program. Finally, the quality of the present model and feasibility of our research owes much to the very kind help from H.L. Tolman (NOAA/NCEP),P.A.E.M. Janssen and Jean Bidlot (ECMWF) and Bertrand Chapron and Jean-François Piolle (Ifremer). The model configuration was initially built by F. Collard who designed the tool to produce the subgrid island mask from a coastline database. N.R. acknowledges the support of a CNRS-DGA doctoral research grant. This work was partially funded by the Groupe Mission Mercator-Coriolis.

\section{References}

Acreman, D., Jeffery, C., 2007. The use of argo for validation and tuning of mixed layer models. Ocean Modelling 19, 53-69.

Agrawal, Y. C., Terray, E. A., Donelan, M. A., Hwang, P. A., Williams, A. J., Drennan, W., Kahma, K., Kitaigorodskii, S., 1992. Enhanced dissipation of kinetic energy beneath breaking waves. Nature 359, 219-220.

Alves, J. H. G. M., Banner, M. L., Young, I. R., 2003. Revisiting the Pierson- 
Moskowitz asymptotic limits for fully developed wind waves. J. Phys. Oceanogr. 33, 1301-1323.

Ardhuin, F., Herbers, T. H. C., Jessen, P. F., O'Reilly, W. C., 2003. Swell transformation across the continental shelf. part II: validation of a spectral energy balance equation. J. Phys. Oceanogr. 33, 1940-1953.

Ardhuin, F., Herbers, T. H. C., Watts, K. P., van Vledder, G. P., Jensen, R., Graber, H., 2007. Swell and slanting fetch effects on wind wave growth. J. Phys. Oceanogr. 37 (4), 908-931.

Ardhuin, F., Jenkins, A. D., 2006. On the interaction of surface waves and upper ocean turbulence. J. Phys. Oceanogr. 36 (3), 551-557.

Ardhuin, F., Martin-Lauzer, F.-R., Chapron, B., Craneguy, P., GirardArdhuin, F., Elfouhaily, T., 2004. Dérive à la surface de l'océan sous l'effet des vagues. Comptes Rendus Géosciences 336, 1121-1130.

Ardhuin, F., Rascle, N., Belibassakis, K. A., 2008. Explicit wave-averaged primitive equations using a generalized lagrangian mean. Ocean Modelling 20, 35-60.

Banner, M. L., Babanin, A. V., Young, I. R., 2000. Breaking probability for dominant waves on the sea surface. J. Phys. Oceanogr. 30, 3145-3160.

URL http://ams . allenpress . com/archive/1520-0485/30/12/pdf/i1520-0485-30-12-3145.pd

Barnier, B., Madec, G., Penduff, T., Molines, J.-M., Treguier, A.-M., Sommer, J. L., Beckmann, A., Biastoch, A., Böning, C., Dengg, J., Derval, C., Durand, E., Gulev, S., Remy, E., Talandier, C., Theetten, S., Maltrud, M., McClean, J., Cuevas, B. D., 2006. Impact of partial steps and momentum advection schemes in a global ocean circulation model at eddy-permitting resolution. Ocean Modelling 56, 543567.

Bidlot, J., Abdalla, S., Janssen, P., 2005. A revised formulation for ocean wave dissipation in CY25R1. Tech. Rep. Memorandum R60.9/JB/0516, Research Department, ECMWF, Reading, U. K.

Bidlot, J., Janssen, P., Abdalla, S., 2007a. A revised formulation of ocean wave dissipation and its model impact. Tech. Rep. Memorandum 509, ECMWF, Reading, U. K.

Bidlot, J.-R., Holmes, D. J., Wittmann, P. A., Lalbeharry, R., Chen, H. S., 2002. Intercomparison of the performance of operational ocean wave forecasting systems with buoy data. Weather and Forecasting 17, 287-309. URL http://ams . allenpress . com/archive/1520-0434/17/2/pdf/i1520-0434-17-2-287.pdf

Bidlot, J.-R., Li, J.-G., Wittmann, P., Fauchon, M., Chen, H., Lefvre, J., Bruns, T., Greenslade, D., Ardhuin, F., Kohno, N., Park, S., Gomez, M., 2007b. Inter-comparison of operational wave forecasting systems. In: Proceedings, 10th Int. WOrkshop of Wave Hindcasting and Forecasting, Hawaii. URL http://www. waveworkshop.org/10thWaves/Papers/paper_10th_workshop_Bidlot_at_al.]

Bister, M., Emanuel, K. A., 1998. Dissipative heating and hurricane intensity. Meteorol. Atmos. Phys. 65, 233-240.

Bonekamp, H., Komen, G. J., Sterl, A., 2002. Statistical comparisons of observed and ECMWF modeled open ocean surface drag. J. Phys. Oceanogr. $32,1010-1027$. 
Burchard, H., 2001. Simulationg the wave-enhanced layer under breaking surface waves with two-equation turbulence models. J. Phys. Oceanogr. 31, 3133-3145.

Businger, J. A., Wyngaard, J. C., Izumi, I., Bradley, E. F., 1971. Flux-profile relationships in the atmospheric surface layer. J. Atmos. Sci. 28, 181-189. URL http://ams . allenpress . com/archive/1520-0469/28/2/pdf/i1520-0469-28-2-181.pdf

Chapron, B., Collard, F., Ardhuin, F., 2005. Direct measurements of ocean surface velocity from space: interpretation and validation. J. Geophys. Res. 110 (C07008), doi:10.1029/2004JC002809.

Collard, F., Ardhuin, F., Chapron, B., 2005. Extraction of coastal ocean wave fields from SAR images. IEEE J. Oceanic Eng. 30 (3), 526-533.

Craig, P. D., Banner, M. L., 1994. Modeling wave-enhanced turbulence in the ocean surface layer. J. Phys. Oceanogr. 24, 2546-2559.

Craik, A. D. D., Leibovich, S., 1977. The generation of Langmuir circulations by an instability mechanism. J. Fluid Mech. 81, 209-223.

Dalrymple, R. A., 1974. A finite amplitude wave on a linear shear current. J. Geophys. Res. 79, 4498-4504.

Dean, R. G., 1965. Stream function representation of nonlinear ocean waves. J. Geophys. Res. 70, 4561-4572.

Dobson, F. W., 1971. Measurements of atmospheric pressure on windgenerated sea waves. J. Fluid Mech. 48, 91-127.

Donelan, M., 1990. The sea. Vol. 9. Wiley \& Sons, New York, pp. 239-292, ocean Engineering Science.

Donelan, M. A., 1998. Air-water exchange processes. In: Imberger, J. (Ed.), Physical Processes in Lakes and Oceans. American Geophysical Union, Washington, D.C., pages 18-36, iSBN 0-87590-268-5.

Donelan, M. A., 1999. Wind-induced growth and attenuation of laboratory waves. In: Sajjadi, S. G., H.Thomas, N., Hunt, J. C. R. (Eds.), Wind-overwave couplings. Clarendon Press, Oxford, U. K., pp. 183-194.

Donelan, M. A., Pierson, Jr., W. J., 1987. Radar scattering and equilibrium ranges in wind-generated waves with application to scatterometry. J. Geophys. Res. 92 (C5), 4971-5029.

Drennan, W. M., Taylor, P. K., Yelland, M. J., 2005. Parameterizing the sea surface roughness. J. Phys. Oceanogr. 35, 835-848.

Elfouhaily, T., Chapron, B., Katsaros, K., Vandemark, D., 1997. A unified directional spectrum for long and short wind-driven waves. J. Geophys. Res. 102 (C7), 15781-15796.

ESA, March 2002. ENVISAT RA-2/MWR product handbook. Tech. Rep. POTN-ESR-RA-0050.

Fairall, C. W., Bradley, E. F., Hare, J. E., Grachev, A. A., Edson, J. B., 2003. Bulk parameterization of air-sea fluxes: updates and verification for the COARE algorithm. Journal of Climate 16, 571-591.

Feng, H., Vandemark, D., Quilfen, Y., Chapron, B., Beckley, B., 2006. Assessment of wind-forcing impact on a global wind-wave model using the topex altimeter. Ocean Eng. 33, 1431-1461, doi:10.1016/j.oceaneng.2005.10.015. 
Garrett, C., 1976. Generation of Langmuir circulations by surface waves - a feedback mechanism. J. Mar. Res. 34, 117-130.

Gaspar, J. P., Grégoris, Y., Lefevre, J. M., 1990. A simple eddy kinetic energy model for simulations of oceanic vertical mixing : Tests at station Papa and long-term upper ocean study site. J. Geophys. Res. 95 (C9), 16179-16193.

Gemmrich, J. R., Farmer, D. M., 2004. Near-surface turbulence in the presence of breaking waves. J. Phys. Oceanogr. 34, 1067-1086.

Gemmrich, J. R., Mudge, T. D., Polonichko, V. D., 1994. On the energy input from wind to surface waves. J. Phys. Oceanogr. 24, 2413-2417.

Grachev, A. A., Fairall, C. W., Hare, J. E., Edson, J. B., Miller, S. D., 2003. Wind stress vector over ocean waves. J. Phys. Oceanogr. 33, 2408-2429.

Hanson, J. L., Phillips, O. M., 2001. Automated analysis of ocean surface directional wave spectra. J. Atmos. Ocean Technol. 18, 277-293.

Harcourt, R. R., D'Asaro, E. A., Dec. 2006. Large Eddy Simulation of Langmuir Turbulence in Pure Wind Seas. AGU Fall Meeting Abstracts, A562+.

Hasselmann, K., 1970. Wave-driven inertial oscillations. Geophys. Fluid Dyn. $1,463-502$.

J.-R., B., Holt, M., 2006. Verification of operational global and regional wave forecasting systems against measurements from moored buoys. Tech. Rep. 30 WMO/TDNo.1333, World Meteorological Organization, Joint Commission on Oceanography and Marine Meteorology.

Janssen, P., Bidlot, J.-R., Abdalla, S., Hersbach, H., 2005. Progress in ocean wave forecasting at ECMWF. Tech. Rep. Memorandum 478, Research Department, ECMWF, Reading, U. K.

Janssen, P. A. E. M., 2007. Progress in ocean wave forecasting. J. Comp. Phys.In press.

Janssen, P. A. E. M., Saetra, O., Wettre, C., Hersbach, H., 2004. Impact of the sea state on the atmosphere and ocean. Annales Hydrographiques $6 \mathrm{e}$ série, vol. 3 (772), 3-1-3-23.

Jarosz, E., Mitchell, D. A., Wang, D. W., Teague, W. J., 2007. Bottom-up determination of air-sea momentum exchange under a major tropical cyclone. Science 315, 1707-1709.

Kenyon, K. E., 1969. Stokes drift for random gravity waves. J. Geophys. Res. 74, 6991-6994.

Kerbaol, V., Chapron, B., Vachon, P., 1998. Analysis of ers-1/2 synthetic aperture radar wave mode imagettes. J. Geophys. Res. 103 (C4), 7833-7846.

Kitaigorodskii, S. A., 1994. A note on the influence of breaking wind waves on the aerodynamic roughness of the sea surface as seen from below. Tellus 46A, 681-685.

Komen, G. J., Hasselmann, K., Hasselmann, S., 1984. On the existence of a fully developed windsea spectrum. J. Phys. Oceanogr. 14, 1271-1285.

Kudryavtsev, V. N., Makin, V. K., 2004. Impact of swell on the marine atmospheric boundary layer. J. Phys. Oceanogr. 34, 934-949.

Kudryavtsev, V. N., Makin, V. K., Chapron, B., 1999. Coupled sea surfaceatmosphere model. 2. spectrum of short wind waves. J. Geophys. Res. 104, 
$7625-7639$.

Lamb, H., 1932. Hydrodynamics, 6th Edition. Cambridge University Press, Cambridge, England.

Langmuir, I., 1938. Surface motion of water induced by wind. Science 87, $119-123$.

Li, M., Zahariev, K., Garrett, C., 1995. Role of Langmuir circulation in the deepening of the ocean surface mixed layer. Science 25, 1955-1957.

Long, C. E., Resio, D. T., 2007. Wind wave spectral observations in Currituck Sound, North Carolina. J. Geophys. Res. 112, C05001.

Magne, R., Belibassakis, K., Herbers, T. H. C., Ardhuin, F., O’Reilly, W. C., Rey, V., 2007. Evolution of surface gravity waves over a submarine canyon. J. Geophys. Res. 112, C01002.

McIntyre, M. E., 1981. On the 'wave momentum' myth. J. Fluid Mech. 106, 331-347.

McWilliams, J. C., Restrepo, J. M., 1999. The wave-driven ocean circulation. J. Phys. Oceanogr. 29, 2523-2540.

Mellor, G., 2003. The three-dimensional current and surface wave equations. J. Phys. Oceanogr. 33, 1978-1989, corrigendum, vol. 35, p. 2304, 2005.

Mellor, G., Blumberg, A., 2004. Wave breaking and ocean surface layer thermal response. J. Phys. Oceanogr. 34, 693-698.

Mellor, G. L., Yamada, T., 1982. Development of a turbulence closure model for geophysical fluid problems. Rev. Geophys. Space Phys. 20 (C2), 851-875.

Melville, W. K., Verron, F., White, C. J., 2002. The velocity field under breaking waves: coherent structures and turbulence. J. Fluid Mech. 454, 203-233.

Miche, A., 1944. Mouvements ondulatoire de la mer en profondeur croissante ou décroissante. forme limite de la houle lors de son déferlement. application aux digues maritimes. Troisième partie. Forme et propriétés des houles limites lors du déferlement. Croissance des vitesses vers la rive. Annales des Ponts et Chaussées Tome 114, 369-406.

Naval Oceanographic Office, NOAA Laboratory for Satellite Altimetry, March 2002. GEOSAT Follow-On GDR user's handbook. Tech. Rep. NOAA/NESDIS/ORA :E/RA31, 1315 East-West Highway 3620, Silver Spring, MD 20910-328, USA.

Noh, Y., 1996. Dynamics of diurnal thermocline formation in the oceanic mixed layer. J. Geophys. Res. 26, 2189-2195.

Noh, Y., Kim, H. J., 1999. Simulations of temperature and turbulence structure of the oceanic boundary layer with the improved near-surface process. J. Geophys. Res. 104 (C7), 15621-15634.

Noh, Y., Min, H. S., Raasch, S., 2004. Large eddy simulation of the ocean mixed layer: the effects of wave breaking and Langmuir circulation. J. Phys. Oceanogr. 34, 720-733.

Phillips, O. M., 1958. The equilibrium range in the spectrum of wind-generated waves. J. Fluid Mech. 4, 426-433.

Phillips, O. M., 1977. The dynamics of the upper ocean. Cambridge University Press, London, 336 p. 
Picot, N., Case, K., Desai, S., Vincent, P., 2003. PODAAC user handbook. IGDR and GDR Jason products. Tech. Rep. SMM-MU-M5-OP-13184-CN (AVISO), JPL D-21352 (PODAAC).

Pierson, Jr, W. J., Moskowitz, L., Dec. 1964. A proposed spectral form for fully developed wind seas based on the similarity theory of S. A. Kitaigorodskii. J. Geophys. Res. 69 (24), 5,181-5,190.

Polton, J. A., Lewis, D. M., Belcher, S. E., 2005. The role of wave-induced Coriolis-Stokes forcing on the wind-driven mixed layer. J. Phys. Oceanogr. $35,444-457$.

Powell, M. D., Houston, S. H., 1998. Surface wind fields of 1995 hurricanes erin, opal, luis, marilyn, and roxanne at landfall. Mon. Weather Rev. 126, 1259-1273.

URL http://ams . allenpress . com/archive/1520-0493/126/5/pdf/i1520-0493-126-5-1259.pd

Powell, M. D., Vickery, P. J., Reinhold, T. A., 2003. Reduced drag coefficient for high wind speeds in tropical cyclones. Nature 422, 279-283.

Queffeulou, P., 2004. Long term validation of wave height measurements from altimeters. Marine Geodesy 27, 495-510, dOI: 10.1080/01490410490883478.

Queffeulou, P., 2006. Altimeter wave height validation - an update. In: Proceedings of OSTST meeting, Venice, Italy, March 16-18. Available at http://www.jason.oceanobs.com/html/swt/posters2006_uk.html.

Quéré, C. L., Rödenbeck, C., Buitenhuis, E. T., Conway, T. J., Langenfelds, R., Gomez, A., Labuschagne, C., Ramonet, M., Nakazawa, T., Metzl, N., Gillett, N., Heimann, M., 2007. Saturation of the Southern Ocean $\mathrm{CO}_{2}$ sink due to recent climate change. Science.

Rascle, N., 2007. Influence of waves on the ocean circulation (in english with introduction in french: impact des vagues sur la circulatuion océanique). Ph.D. thesis, Université de Bretagne Occidentale, available at http://tel.archivesouvertes.fr/tel-00182250/fr/.

URL http://tel .archives-ouvertes .fr/tel-00182250/fr/

Rascle, N., Ardhuin, F., Terray, E. A., 2006. Drift and mixing under the ocean surface. part 1: a coherent one-dimensional description with application to unstratified conditions. J. Geophys. Res. 111, C03016, doi:10.1029/2005JC003004.

Sloss, P. W., 1993. Global relief cd-rom. Tech. rep., Marine Geology and Geophysics Division, U. S. National Geophysical Data Center (NOAA/NESDIS/NGDC/MGGD). URL http://ww.ngdc.noaa.gov/mgg/global/relief/ETOP05/readme.txt

Smith, J., 1998. Evolution of Langmuir circulation during a storm. J. Geophys. Res. 103 (C6), 12649-12668.

URL http://jerry .ucsd.edu/JSmith_PDF/1998-jgro103-Smith-LCinStorm .pdf

Smith, J. A., 2001. Observations and theories of Langmuir circulation: a story of mixing. In: Lumley, J. (Ed.), Fluid Mechanics and the Environment: Dynamical Approaches. Springer, New York, pp. 295-314. URL http://jerry .ucsd.edu/JSmith_PDF/2001-Smith-aStoryOfMixing.pdf

Smith, J. A., 2006. Wave-current interactions in finite-depth. J. Phys. 
Oceanogr. 36, 1403-1419.

Snyder, R. L., Dobson, F. W., Elliot, J. A., Long, R. B., 1981. Array measurement of atmospheric pressure fluctuations above surface gravity waves. J. Fluid Mech. 102, 1-59.

Soloviev, A., Lukas, R., 2003. Observation of wave-enhanced turbulence in the near-surface layer of the ocean during TOGA COARE. Deep Sea Res. I 50, 371-395.

Sriver, R. L., Huber, M., 2007. Observational evidence for an ocean heat pump induced by tropical cyclones. Nature 577-580, L20605.

Stacey, M. W., 1999. Simulation of the wind-forced near-surface circulation in Knight Inlet: A parameterization of the roughness length. J. Phys. Oceanogr. 29, 1363-1367.

Stacey, M. W., Pond, S., 1997. On the Mellor-Yamada turbulence closure scheme: the surface boundary condition for $q^{2}$. J. Phys. Oceanogr. 27, 20812086.

Terray, E. A., Donelan, M. A., Agrawal, Y. C., Drennan, W. M., Kahma, K. K., Williams, A. J., Hwang, P. A., Kitaigorodskii, S. A., 1996. Estimates of kinetic energy dissipation under breaking waves. J. Phys. Oceanogr. 26, 792-807.

Terray, E. A., Drennan, W. M., Donelan, M. A., 2000. The vertical structure of shear and dissipation in the ocean surface layer. In: Proc. Symp. on Air-Sea Interaction, Sydney. University of New South Wales, pp. 239-245.

Tolman, H. L., 2002. Validation of WAVEWATCH-III version 1.15. Tech. Rep. 213, NOAA/NWS/NCEP/MMAB.

Tolman, H. L., 2003. Treatment of unresolved islands and ice in wind wave models. Ocean Modelling 5, 219-231.

Tolman, H. L., 2007. The 2007 release of WAVEWATCH III. In: Proceedings, 10th Int. Workshop of Wave Hindcasting and Forecasting, Hawaii. URL http://www . waveworkshop.org/10thWaves/Papers/oahu07_Q4.pdf

Tolman, H. L., Chalikov, D., 1996. Source terms in a third-generation wind wave model. J. Phys. Oceanogr. 26, 2497-2518.

Wang, D. W., Mitchell, D. A., Teague, W. J., Jarosz, E., Hulbert, M. S., 2005. Extreme waves under hurricane Ivan. Science 309, 896.

Weber, J. E., Førland, E., 1990. Effect of the air on the drift velocity of water waves. J. Fluid Mech. 218, 619-640.

Wessel, P., Smith, W. H. F., 1996. A Global Self-consistent Hierarchical, Highresolution Shoreline database. J. Geophys. Res. 101, 8741-8743.

WISE Group, 2007. Wave modelling the state of the art. Progress in Oceanography $75,603-674$.

Wunsch, C., Ferrari, R., 2003. Vertical mixing, energy, and the general circulation of the oceans. Annu. Rev. Fluid Mech. 36, 281-314.

Xu, Z., Bowen, A. J., 1994. Wave- and wind-driven flow in water of finite depth. J. Phys. Oceanogr. 24, 1850-1866. 